\author{
UNIVERSIDADE DE SÃO PAULO \\ FACULDADE DE ODONTOLOGIA DE RIBEIRÃO PRETO
}

Análise da diferenciação osteoblástica in vitro sobre superfícies de materiais vítreos e vitrocerâmicos bioativos

Olívia Cherubin Alves

Ribeirão Preto 


\section{Olívia Cherubin Alves}

\section{Análise da diferenciação osteoblástica in vitro sobre superfícies de materiais vítreos e vitrocerâmicos bioativos}

Dissertação apresentada à Faculdade de Odontologia de Ribeirão Preto - USP, como parte dos requisitos para obtenção do título de Mestre em Biologia Oral.

Orientador: Paulo Tambasco de Oliveira

Ribeirão Preto 
Autorizo a reprodução e divulgação total ou parcial deste trabalho, por qualquer meio convencional ou eletrônico, para fins de estudo e pesquisa, desde que citada a fonte.

FICHA CATALOGRÁFICA

Alves, Olívia Cherubin

Análise da diferenciação osteoblástica in vitro sobre superfícies de materiais vítreos e vitrocerâmicos bioativos. Ribeirão Preto, 2012.

64p.: il.; $30 \mathrm{~cm}$

Dissertação de Mestrado, apresentada à Faculdade de Odontologia de Ribeirão Preto da Universidade de São Paulo.

Área de concentração: Biologia Oral.

Orientador: De Oliveira, Paulo Tambasco

1. Cultura de células. 2. Diferenciação celular. 3. Expressão gênica. 4. Osteoblastos. 5. Vidros bioativos. 6. Vitrocerâmicas bioativas. 
Trabalho realizado nos Laboratórios de Cultura de Células e de Biologia Molecular da Faculdade de Odontologia de Ribeirão Preto da Universidade de São Paulo, com auxílio financeiro da Fundação de Amparo à Pesquisa do Estado de São Paulo (FAPESP). 


\section{FOLHA DE APROVAÇÃO}

Olívia Cherubin Alves

Análise da diferenciação osteoblástica in vitro sobre superfícies de materiais vítreos e vitrocerâmicos bioativos.

Dissertação apresentada à Faculdade de Odontologia de Ribeirão Preto da Universidade de São Paulo para obtenção do título de Mestre. Área de Concentração: Biologia Oral

Aprovado em: / 2012

Banca Examinadora

Prof. Dr.

Instituição: Assinatura:

Prof. Dr.

Instituição: Assinatura:

Prof. Dr. Instituição: Assinatura: 
Dedico este trabalho aos meus pais, Adauto e Goreti, e irmãos, Natália e Victor, pelo apoio, amor incondicional, incentivo, compreensão e por tudo que fizeram por mim até hoje. Cheguei até aqui por vocês. Amo vocês! 
À Universidade de São Paulo, representada pelo reitor Prof. Dr. João Grandino Rodas.

À Faculdade de Odontologia de Ribeirão Preto - USP, representada pelo diretor Prof. Dr. Valdemar Mallet da Rocha Barros.

À Fundação de Amparo à Pesquisa do Estado de São Paulo (FAPESP), pela bolsa de mestrado e auxílio à pesquisa concedidos.

Ao meu orientador, Prof. Dr. PAULO TAMBASCO DE OLIVEIRA, pela orientação, a qual tive a imensa sorte de ter conseguido manter desde a iniciação científica, pela confiança, pela paciência, pela amizade e pela grande oportunidade de aprendizado e crescimento pessoal que me proporcionou. Você é uma inspiração como pesquisador, cientista e mestre. Uma pessoa correta, simples e com um coração enorme que admiro muito! Muito obrigada por tudo!

Ao Prof. Dr. Adalberto Luiz Rosa, por todo auxílio ao projeto, pela oportunidade de conviver e dividir conhecimentos, experiências e pela amizade. Foi uma honra tê-lo como co-orientador.

Aos colegas do curso de mestrado, tanto da turma da Biologia Oral quanto das de Reabilitação Oral e Cirurgia, pela oportunidade de conhecê-los, pela troca de experiências e amizade. Em especial à Gabriela, Cristiane e Juliana, pelo apoio, pelos momentos de alegria compartilhados e pela amizade especial que começamos. Sempre terão meu carinho, torço por vocês.

Aos amigos do Laboratório de Cultura de Células, Larissa Sverzut, Luciana Bastos, Willian, Tiago, Emanuella, Gabriela Rodrigues, Luciana Maia, Carolina, Samuel, Milla, Renan e Rogério, por todos os momentos que tornaram os dias de trabalho mais agradáveis.

Aos amigos queridos Larissa de Castro e Lucas Novaes. Não existem palavras para expressar o quanto sou grata por toda colaboração de vocês, em todos os sentidos. Vocês são parte do laboratório e indispensáveis para realização de todo nosso trabalho. Obrigada por toda atenção, por cada palavra de carinho nos momentos mais difíceis e pela amizade. 
Ao querido amigo ROGER, por toda atenção, amizade e carinho. Agradeço por ter tido paciência e generosidade de me ensinar e ajudar a desenvolver o nosso trabalho. Mesmo nos momentos difíceis era muito bom saber que sempre podia confiar na sua ajuda. Sempre terá minha amizade e admiração. Obrigada por tudo!

À amiga Gabriela Alonso, por toda sua contribuição ao desenvolvimento do nosso trabalho, pela amizade e conhecimento compartilhado.

À querida amiga Fabíola Singaretti de Oliveira, pela orientação e ajuda indispensáveis na realização dos experimentos desse projeto. Obrigada pela paciência, pela amizade e carinho.

Aos queridos amigos, professores e alunos do Centro de Atendimento Especializado em Diagnóstico Oral (CAEDO), em especial à Profa. Dra. Suzie Aparecida de Lacerda e ao Prof. Dr. Luiz Guilherme Brentegani, que me deram a oportunidade desde a graduação até o treinamento no PAE, em contribuir com a minha formação como futura docente, permitindo consolidar minha realização como profissional e decisão quanto à prática da docência. Obrigada por toda disponibilidade, amizade e carinho. Sempre serei grata por todo apoio, incentivo e confiança. Sempre serão uma inspiração pra mim.

A toda minha família e ao Rafael, pelo amor e presença constante em minha vida. 


\section{RESUMO}

\section{ALVES, O.C. Análise da diferenciação osteoblástica in vitro sobre superfícies}

de materiais vítreos e vitrocerâmicos bioativos. 2012. 64p. Dissertação (Mestrado) - Faculdade de Odontologia de Ribeirão Preto, Universidade de São Paulo, Ribeirão Preto, 2012.

Materiais vítreos e vitrocerâmicos bioativos podem ser usados particulados ou como scaffolds em diferentes tratamentos de defeitos ósseos. Tratamentos térmicos que possibilitam o desenvolvimento de scaffolds a partir de composições de vidros bioativos introduzem fases cristalinas em sua estrutura amorfa com potencial impacto na bioatividade e biocompatibilidade do material. O objetivo do presente estudo foi avaliar, qualitativa e quantitativamente, o desenvolvimento do fenótipo osteogênico de culturas de células osteoblásticas sobre substratos vítreos e vitrocerâmicos bioativos. Células MC3T3-E1 foram cultivadas em condições osteogênicas por períodos de até 21 dias sobre superfícies de Bioglass ${ }^{\circledR} 45 \mathrm{~S} 5$, de duas preparações de vitrocerâmica bioativa e altamente cristalina, Biosilicato ${ }^{\circledR}$ e Biosilicato ${ }^{\circledR}$ para scaffold, e de borosilicato (vidro bioinerte). Foram avaliados, nos períodos de 7, 12 e 21 dias, morfologia celular, formação de matriz mineralizada e expressão de genes relacionados à osteogênese. Os resultados mostraram confluência das culturas sobre as superfícies de vidros e vitrocerâmicas, com progressiva formação de multicamadas celulares. A quantificação de vermelho de Alizarina revelou aumento de mineralização para culturas sobre materiais bioativos, com os maiores valores para Biosilicato ${ }^{\circledR}$ para scaffold. Expressão diferencial de genes foi observada nos 3 períodos de culturas sobre os materiais vítreo e vitrocerâmicos bioativos em comparação ao vidro bioinerte e sobre as vitrocerâmicas em comparação ao vidro bioativo. Os resultados permitem concluir que modificações em aspectos químicos de materiais vítreos e vitrocerâmicos, com efeitos sobre sua bioatividade, resultam em alteração do potencial osteogênico e do perfil de expressão gênica de células osteoblásticas in vitro. A maior atividade osteogênica sobre o Biosilicato ${ }^{\circledR}$ para scaffold permite considerar esse material um potencial candidato para aplicações em defeitos ósseos.

Palavras-chave: cultura de células, diferenciação celular, expressão gênica, osteoblastos, vidros bioativos, vitrocerâmicas bioativas. 


\begin{abstract}
ALVES, O.C. In vitro osteoblastic differentiation on bioactive glass and glassceramic surfaces. 2012. 64p. Thesis (Masters Degree) - Faculdade de Odontologia de Ribeirão Preto, Universidade de São Paulo, Ribeirão Preto, 2012.
\end{abstract}

Bioactive glasses and glass-ceramics have been used as bone substitutes in either particulate or scaffold forms. Various thermal treatments that allow the development of scaffolds from bioactive glasses may create varied proportions of new crystalline phases in the amorphous phase with a potential impact on the bioactivity and biocompatibility of the material. The aim of the present in vitro study was to qualitatively and quantitatively evaluate the development of the osteogenic phenotype in osteoblastic cell cultures grown on bioactive glass and glass-ceramic surfaces. MC3T3-E1 cells, subclone 14, were cultured under an osteogenic condition for periods of up to 21 days on the following disc surfaces: Bioglass ${ }^{\circledR} 45 S 5$ (bioactive glass), Biosilicate ${ }^{\circledR}$ (bioactive glass-ceramic), Biosilicate ${ }^{\circledR}$ as the material for scaffold preparation (Bio-sc, bioactive glass-ceramic), and borosilicate (bioinert glass). At days 7, 12, and 21 post-plating, cell morphology, mineralized matrix formation and the expression profile of genes associated with osteogenesis were evaluated. Epifluorescence of actin cytoskeleton and DAPI DNA stain revealed confluent cell cultures at day 7 for all groups, with progressive cell multilayering formation. The quantitative analysis of Alizarin red-stained cultures at day 21 revealed significantly enhanced mineralization in cultures grown on bioactive materials compared with the ones on borosilicate and the highest absorbance intensities for the Bio-sc group. Differential gene expression profiles were detected at the three time points evaluated in cultures grown on the bioactive materials in comparison with borosilicate, and on the glass-ceramics in comparison with Bioglass ${ }^{\circledR} 45 S 5$. From the results presented, it can be concluded that changes in chemical characteristics of glass and glass-ceramic that may have an impact on their bioactivity index can affect the osteogenic potential and the gene expression profile of osteoblastic cells in vitro. The highest osteogenic activity on Bio-sc renders this material a good candidate for bone defect applications.

Key-words: cell culture, cell differentiation, gene expression, osteoblast, bioactive glass, bioactive glass-ceramic. 
1 INTRODUÇÃO

2 PROPOSIÇÃO

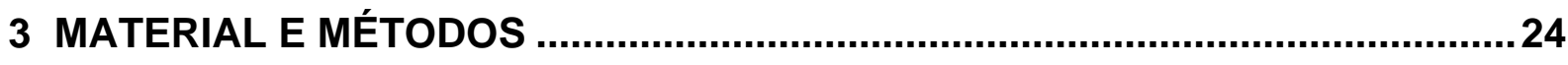

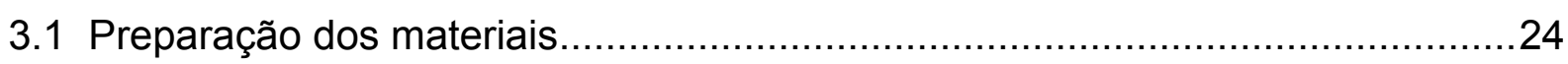

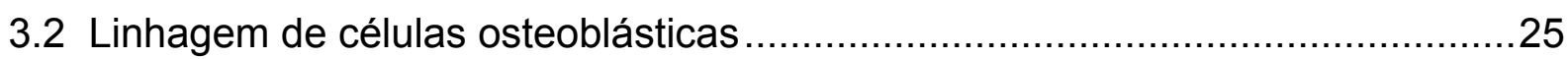

3.3 Morfologia e localização de marcadores iniciais da diferenciação osteoblástica.......26

3.4 Detecção de acúmulos de cálcio (formação de matriz mineralizada).................27

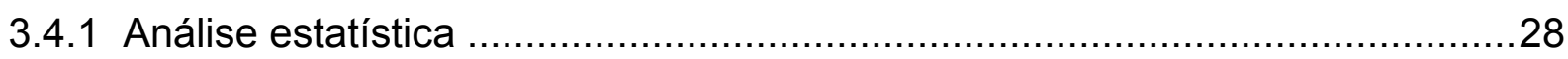

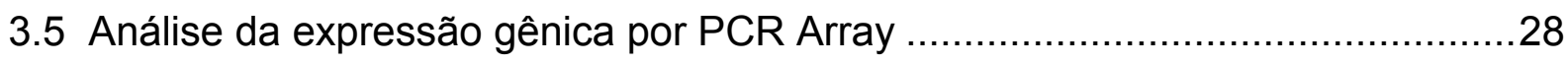

3.5.1 Método de extração de RNA e confecção de cDNA ……………...................28

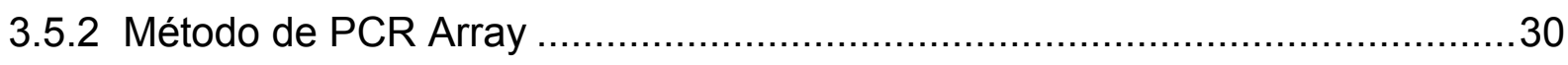

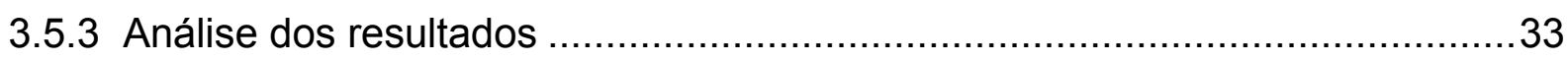

4 RESULTADOS

4.1 Morfologia celular, imunolocalização de BSP e atividade de fosfatase alcalina in

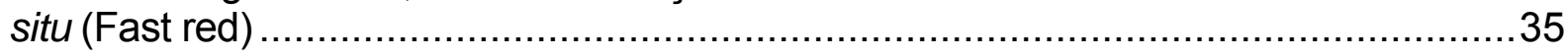

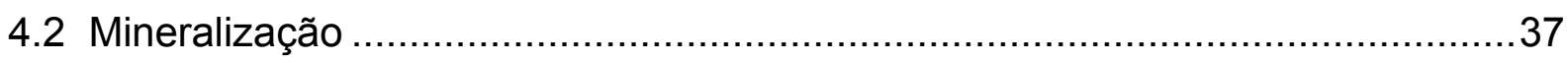

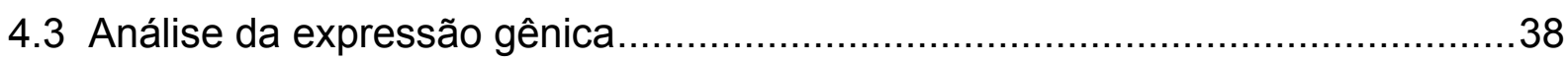

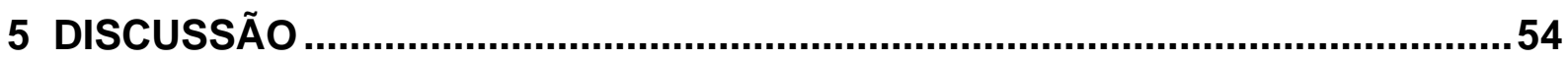

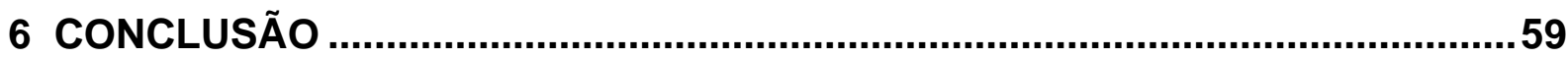

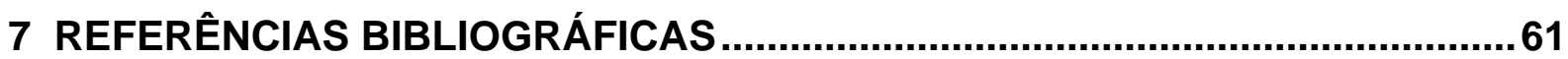




\section{INTRODUÇÃO}

Diferentes aspectos das interações de células e tecidos biológicos com os biomateriais são determinados, em parte, pelas características físicas e químicas da superfície do material. O desenvolvimento de materiais para implantação que favoreçam um reparo ósseo rápido e controlado e que resulte em regeneração tecidual é o principal objetivo da pesquisa com os substitutos ósseos (BRUNSKI et al., 2000). A produção de biomateriais deve ser baseada na compreensão e quantificação das reações celulares em substratos naturais e artificiais. Esse princípio baseia-se em evidências de que a superfície do material se constitui em fator crítico na determinação de sua biocompatibilidade e no processo de integração com os tecidos biológicos (NANCl et al., 1998).

Nas últimas décadas, novos materiais, naturais e sintéticos, têm sido desenvolvidos com o objetivo de substituir o tecido ósseo (PULEO et al., 1991). Além de proporcionarem reduzida morbidade, esses biomateriais possuem como benefícios a facilidade para sua disponibilização e esterilização (MOORE et al., 2001). Entre os principais biomateriais para implantação em osso utilizados em Ortopedia e Odontologia estão os vidros e as cerâmicas de Ca e P (por exemplo, Bioglass ${ }^{\circledR} 45 S 5$ e hidroxiapatita, respectivamente), os metais (titânio e aço cirúrgico) e os polímeros (poli (ácido lático) e polimetilmetacrilato). No espectro de biocompatibilidade, as cerâmicas de Ca e P e alguns vidros, como o Bioglass ${ }^{\circledR} 45 S 5$, são considerados materiais bioativos (HENCH; WILSON, 1984).

O vidro Bioglass ${ }^{\circledR} 45 S 5$, definido como gold standard para aplicação em procedimentos regenerativos ósseos, tem sido considerado o material que apresenta 
o maior índice de bioatividade. Há evidências experimentais de aumento da formação de matriz mineralizada in vitro sobre Bioglass ${ }^{\circledR} 45 S 5$, por meio de estimulação dos processos de diferenciação e proliferação de células da linhagem osteoblástica (XYNOS et al., 2000a; XYNOS et al., 2000b; LOSSDORFER et al., 2004; HATTAR et al., 2005), tanto in vitro quanto in vivo (DUCHEYNE; QIU, 1999). De fato, pelo menos sete famílias de genes são ativadas quando osteoblastos humanos em culturas primárias são expostos aos produtos da dissolução iônica dos vidros bioativos, incluindo genes que codificam proteínas que estão associadas a esses processos (HENCH et al., 2000; XYNOS et al., 2001; LOTY et al., 2001; $\mathrm{HENCH}$ et al., 2002). Ainda que apresente características importantes que favoreçam o processo de reparo ósseo, a aplicação de materiais vítreos bioativos na engenharia de tecido é limitada por esses materiais apresentarem propriedades mecânicas inadequadas ao desenvolvimento de scaffolds (arcabouços) (CHEN et al., 2006).

Para contornar essa limitação, uma das estratégias tem sido o desenvolvimento de vitrocerâmicas, por meio de métodos para a cristalização controlada total ou parcial de vidros bioativos (JAMES et al., 1995; CHEN et al., 2006). Assim, vitrocerâmicas bioativas foram desenvolvidas com o intuito de melhorar as propriedades mecânicas dos materiais bioativos, incluindo Ceravital ${ }^{\circledR} \mathrm{e}$ A/W ${ }^{\circledR}$ (BRÖMER et al., 1976; KOKUBO et al., 1985), ou para proporcionar outras propriedades importantes ao material, como é o caso da vitrocerâmica Bioverit ${ }^{\circledR}$, usinável (HENCH; WILSON, 1993). Ainda que vitrocerâmicas apresentem propriedades mecânicas que podem ser superiores às dos vidros, a introdução de algumas fases cristalinas poderia diminuir acentuadamente sua bioatividade (BELLUCCI et al., 2010). O resultado é que os índices de bioatividade das 
vitrocerâmicas disponíveis no mercado são substancialmente mais baixos do que os dos vidros bioativos (HENCH; WEST, 1996).

Neste contexto, o Laboratório de Materiais Vítreos do Departamento de Engenharia de Materiais da Universidade Federal de São Carlos (LaMaV-DEMaUFSCar) desenvolveu e patenteou uma nova vitrocerâmica pertencente ao sistema quaternário $\mathrm{P}_{2} \mathrm{O}_{5}-\mathrm{Na}_{2} \mathrm{O}-\mathrm{CaO}-\mathrm{SiO}_{2}, 100 \%$ cristalina, denominada Biosilicato ${ }^{\circledR}$ (patente WO 2004/074199; Fundação Universidade Federal de São Carlos; Universidade de São Paulo, 2004), visando sua utilização em algumas especialidades médicas e odontológicas. A razão para o desenvolvimento desse novo material baseou-se no princípio de que a cristalinidade altera significativamente as características de fratura dos vidros. A cristalização progressiva do material tende a aumentar suas propriedades mecânicas (PEITL et al., 2012), além de favorecer a formação de partículas menos abrasivas e cortantes quando o material é triturado para a obtenção de pó, aspectos que poderiam ser considerados relevantes para aplicações clínicas específicas. Em estudo pioneiro de nosso grupo de pesquisa, Moura et al. (2007) demontraram que a cristalização total do Biosilicato ${ }^{\circledR}$ promove o aumento de seu índice de bioatividade para níveis superiores aos de vitrocerâmicas comercializadas atualmente (HENCH; WEST, 1996). Além disso, experimentos in vitro mostraram que o Biosilicato ${ }^{\circledR} 100 \%$ cristalino promove aumento significativo do potencial osteogênico de células primárias derivadas de calvárias de ratos em comparação àquelas crescidas sobre materiais controles (Biosilicato $^{\circledR}$ vítreo e Bioglass ${ }^{\circledR}$ 45S5), resultando na formação de áreas mais extensas de matriz mineralizada aos 14 dias. Em outro estudo, avaliando os efeitos do pré-tratamento de superfícies de Biosilicato ${ }^{\circledR}$ por 3 dias com meio de cultura, na presença ou não de soro fetal bovino, De Castro (2009) observou alterações em eventos iniciais de 
interação célula-substrato de culturas primárias osteogênicas, com aumento significativo de viabilidade, proliferação e população celulares e maior expressão de Runx2, BSP e ALP nos 7 primeiros dias; áreas ainda mais extensas de matriz mineralizada foram observadas em culturas sobre superfícies de Biosilicato ${ }^{\circledR}$ condicionadas em meio com soro.

Associados a esses resultados in vitro favoráveis ao desenvolvimento do fenótipo osteogênico, estudos in vivo utilizando diferentes modelos animais demonstraram que a presença de partículas de Biosilicato ${ }^{\circledR}$ em defeitos ósseos permite a formação de matriz óssea mineralizada na interface com o biomaterial (GRANITO et al., 2009; RORIZ et al., 2010; GRANITO et al., 2011). Apesar disso, para a preparação de scaffolds, um dos objetivos originais para o desenvolvimento do Biosilicato $^{\circledR}$, torna-se necessário um tratamento térmico complementar com temperaturas superiores a $800^{\circ} \mathrm{C}$, o que resulta na formação de uma fase cristalina secundária, constituída de fosfato de cálcio (CROVACE, 2009). Scaffolds de Biosilicato $^{\circledR}$ estão em fase inicial de avaliações sobre sua biocompatibilidade e seus efeitos sobre o processo de diferenciação osteoblástica (RENNO et al., 2010). 
2 PROPOSIÇÃO 


\section{PROPOSIÇÃO}

O objetivo do presente estudo foi avaliar, qualitativamente, os aspectos morfológicos e, quantitativamente, a mineralização da matriz extracelular e a expressão de genes relacionados à osteogênese em fases distintas de culturas de células pré-osteoblásticas MC3T3-E1 crescidas sobre substratos vítreos e vitrocerâmicos bioativos. 


\section{MATERIAL E MÉTODOS}

\subsection{Preparação dos materiais}

Discos de Biosilicato ${ }^{\circledR}$, de $2,5 \mathrm{~mm}$ de espessura $\times 12 \mathrm{~mm}$ de diâmetro, foram produzidos pelo LaMaV. A composição e o protocolo de tratamentos térmicos para obtenção do Biosilicato ${ }^{\circledR}$ estão descritos na patente WO 2004/074199. Sílica de alta pureza, carbonato de cálcio, carbonato de sódio e fosfato de sódio foram usados para obter a composição do vidro bioativo Bioglass ${ }^{\circledR} 45 S 5$ e Biosilicato ${ }^{\circledR}$ vítreo. Os materiais foram pesados e misturados por $30 \mathrm{~min}$ em garrafa de polietileno. A fusão ocorreu em temperaturas entre 1250 e $1380{ }^{\circ} \mathrm{C}$ por $3 \mathrm{~h}$ em forno elétrico (Rapid Temp 1710 BL, CM Furnaces Inc., Bloomfield, NJ, EUA). As amostras foram colocadas em molde cilíndrico de grafite nas dimensões $12 \mathrm{~mm}$ x $30 \mathrm{~mm}$ e submetidas à fusão a $460{ }^{\circ} \mathrm{C}$ por $5 \mathrm{~h}$. Para obtenção da vitrocerâmica totalmente cristalizada (Biosilicato ${ }^{\circledR}$ ), os cilindros contendo Biosilicato ${ }^{\circledR}$ vítreo passaram por ciclo de tratamento térmico para promover sua cristalização. Os primeiros ciclos térmicos foram executados em baixas temperaturas para favorecer a nucleação volumétrica dos cristais. Posteriormente, as amostras nucleadas foram submetidas a tratamentos térmicos a uma temperatura superior à de transição do vidro para ocasionar a total cristalização do material. Para a obtenção de Biosilicato ${ }^{\circledR}$ para scaffold, foi realizado um tratamento térmico complementar, com temperaturas superiores a $800^{\circ} \mathrm{C}$. Os cilindros de Biosilicato ${ }^{\circledR}$, Biosilicato ${ }^{\circledR}$ para scaffold, Bioglass ${ }^{\circledR} 45 S 5$ e vidro bioinerte (borosilicato, Pyrex ${ }^{\circledR}$, Corning Inc., Corning, NY, EUA) foram cortados em discos na espessura de $3 \mathrm{~mm}$ usando lâmina de diamante. Por fim, os discos, de $12 \mathrm{~mm}$ de diâmetro, foram polidos com lixas de carbeto de silício na gramatura de 400, imersos 
em álcool isopropílico e limpos em ultra-som. Em seguida, os discos foram lavados e armazenados em álcool isopropílico, para evitar modificações na superfície causadas pela umidade do ar. Para os experimentos com cultura de células, os discos de Biosilicato ${ }^{\circledR}$, Biosilicato ${ }^{\circledR}$ para scaffold, Bioglass ${ }^{\circledR} 45 S 5$ e borosilicato foram previamente esterilizados em calor seco a $180{ }^{\circ} \mathrm{C}$ em forno de Pasteur por $2 \mathrm{~h}$. Para simplificar sua identificação, as siglas para os diferentes materiais definem-se assim:

1) Borosilicato - Boro;

2) Bioglass ${ }^{\circledR} 45 S 5-45 S 5$;

3) Biosilicato ${ }^{\circledR}-$ Bio;

4) Biosilicato ${ }^{\circledR}$ para scaffold - Bio-sc.

\subsection{Linhagem de células osteoblásticas}

As células osteoblásticas MC3T3-E1, sub-clone 14, derivadas de camundongo (QUARLES et al., 1992; FRATZL-ZELMAN et al., 1998; MOFFATT et al., 2008; VETRONI et al., 2009), foram adquiridas junto à ATCC (na sigla em inglês para American Type Culture Collection; Manassas, VA, EUA). Inicialmente, as células foram cultivadas em garrafas de cultura de $75 \mathrm{~cm}^{3}$ (Corning Inc.) com $10 \mathrm{~mL}$ de meio de cultura a-MEM (Invitrogen), 10\% de soro fetal bovino (Invitrogen) e 2,2 $\mathrm{mL}$ de penicilina-estreptomicina (Sigma). Durante todo o tempo de cultivo as células foram mantidas a $37{ }^{\circ} \mathrm{C}$ em atmosfera umidificada, contendo $5 \%$ de $\mathrm{CO} 2$ e $95 \%$ de ar atmosférico e os meios foram trocados a cada 2-3 dias. Após confluência, as células foram removidas dos frascos de cultura por meio de tratamento com EDTA a $1 \mathrm{mM}$ (Gibco, Invitrogen, Grand Island, NY, EUA) e tripsina a 0,25\% (Gibco) e contadas em microscópio por meio de hemocitômetro (Fisher Scientific, Pittsburgh, PA, EUA). As células foram plaqueadas sobre os diferentes substratos vítreos e 
vitrocerâmicos contidos em placas de 24 poços, na densidade de $2 \times 10^{4}$ células/poço, e foram cultivadas em meio osteogênico por períodos de 7, 12 e 21 dias.

\subsection{Morfologia e localização de marcadores iniciais da diferenciação osteoblástica}

Nos tempos de 7, 12 e 21 dias, as células foram fixadas em paraformaldeído a $4 \%$ em tampão fosfato a $0,1 \mathrm{M}, \mathrm{pH} 7,2(\mathrm{~PB})$, por 10 min à temperatura ambiente (TA). Em seguida, as células foram processadas rotineiramente para imunofluorescência indireta (DE OLIVEIRA; NANCI, 2004; DE OLIVEIRA et al., 2007; SCHWARTZ FO et al., 2007). A permeabilização foi feita com solução de Triton X-100 a 0,5\% em PB por 10 min, seguida de bloqueio com leite desnatado a 5\% em PB por 30 min. Foi utilizado anticorpo primário para sialoproteína óssea (1:200, WVID1-9C5, Developmental Studies Hybridoma Bank - DSHB, lowa City, IA, EUA), seguido de anticorpo secundário conjugado com fluoróforo Alexa Fluor 594 (fluorescência vermelha; 1:200, Molecular Probes) em mesma solução de faloidina conjugada com Alexa Fluor 488 (fluorescência verde; 1:200, Molecular Probes), usada para visualização do citoesqueleto de actina. Todas as incubações dos anticorpos foram feitas em atmosfera úmida por $60 \mathrm{~min}$ em TA. Entre cada incubação, as amostras foram lavadas três vezes (5 min cada) em PB. Antes da montagem para observação microscópica, as amostras foram lavadas rapidamente com água destilada e os núcleos celulares, marcados com DAPI (Molecular Probes) a 300 nM por 5 min. Os discos foram montados diretamente em lâminas de vidros, e em seguida, após montagem de lamínula de vidro Fisherbrand $12 \mathrm{~mm}$ (Fisher Scientific) com meio de montagem anti-fade (Vectashield, Vector Labs, EUA) sobre as superfícies contendo células, as amostras foram examinadas utilizando 
microscópio de fluorescência acoplado a uma câmera digital. As imagens adquiridas foram processadas com o programa Adobe Photoshop CS5.1.

Nos mesmos períodos, foi realizado ensaio para visualização da atividade de fosfatase alcalina in situ. O meio de cultura foi removido e os poços foram lavados com solução de Hanks (Hanks' Balanced Salts, Sigma) a 9,8 g/L e NaHCO3 Hybrimax $^{\circledR}$ (Sigma) a $350 \mathrm{mg} / \mathrm{L}$, aquecida a $37^{\circ} \mathrm{C}$. Após esse procedimento foi incubado, em cada poço, $1 \mathrm{~mL}$ de solução tampão Tris (Sigma) a 120 mM, pH 8,4; contendo Fast red TR (Sigma) a 1,8 mM, naftol-ASMX-fosfato (Sigma) a 0,9 mM e dimetilformamida (Merck) 1:9, por 30 min em atmosfera úmida contendo $5 \%$ de CO2 e $95 \%$ de ar atmosférico. Em seguida, a solução foi removida e os poços deixados a secar em TA. Imagens macroscópicas das culturas foram obtidas digitalmente com câmera de alta resolução (Canon EOS Digital Rebel, 6.3 megapixels, com lente macro EF100 f/2.8). As imagens adquiridas foram processadas com o programa Adobe Photoshop CS5.1.

\subsection{Detecção de acúmulos de cálcio (formação de matriz mineralizada)}

Em 21 dias, as culturas da linhagem celular MC3T3-E1 crescidas sobre os discos dos diferentes grupos foram lavadas em solução de Hanks, fixadas em álcool etílico a $70 \%$ a $4{ }^{\circ} \mathrm{C}$ por $60 \mathrm{~min}$ e lavadas em PBS e água destilada sequencialmente. Em seguida, foram coradas com vermelho de alizarina (Alizarin Red S, Sigma) a 2\%, pH 4,2, à TA por 15 min, lavadas com PBS e água destilada e deixadas a secar à TA. Imagens macroscópicas das culturas coradas com ARS foram obtidas digitalmente com câmera de alta resolução (Canon EOS Digital Rebel, 6.3 MP, com lente macro EF100 f/2.8) processadas com o programa Adobe Photoshop CS5.1. 
Acúmulos de cálcio foram quantitativamente determinados pelo método de extração de ARS (GREGORY et al., 2004). Em cada poço contendo os discos dos diferentes materiais corados com ARS, foram adicionados $280 \mu \mathrm{L}$ de ácido acético a $10 \%$ e a placa, deixada sob agitação suave por $30 \mathrm{~min}$. A camada de células foi, então, raspada com um raspador de células e a solução, transferida para tubos de $1,5 \mathrm{~mL}$ e agitada em vortex por $30 \mathrm{~s}$. Em seguida, as amostras foram aquecidas a 85 ${ }^{\circ} \mathrm{C}$ por $10 \mathrm{~min}$, resfriadas em gelo por $5 \mathrm{~min}$ e centrifugadas a $13000 \mathrm{~g}$ por $20 \mathrm{~min}$. De cada grupo experimental, foram transferidos $100 \mu \mathrm{L}$ de sobrenadante para placa de 96 poços e adicionados $40 \mu \mathrm{L}$ de hidróxido de amônio a 10\% em cada poço. As amostras foram lidas em espectrofotômetro ( $\mu$ Quanti, BioTek Instruments), utilizando comprimento de onda de $405 \mathrm{~nm}$. A curva padrão foi realizada com dissoluções sucessivas de ARS de 0,5 a $3 \mathrm{mM}$ em acetato de amônio (ácido acético a 10\% e $\mathrm{NH}_{4} \mathrm{OH}$ a $\left.5 \mathrm{M}\right)$.

\subsubsection{Análise estatística}

Utilizou-se teste paramétrico para dados independentes (ANOVA One-Way), seguido do teste de comparações múltiplas de Holm-Sidak. O nível de significância foi de $5 \%$.

\subsection{Análise da expressão gênica por PCR Array}

\subsubsection{Método de extração de RNA e confecção de cDNA}

Nos tempos de 7, 12 e 21 dias, o meio de cultura foi removido de todos os poços contendo os discos dos diferentes materiais, os quais foram transferidos para uma nova placa para que apenas o RNA das células sobre os discos fosse extraído; 
em seguida, foi adicionado $1 \mathrm{~mL}$ do reagente Trizol (Invitrogen) no primeiro poço. Após intensa pipetagem, para promover lise das células, esta mistura foi transferida para o próximo poço de cultura celular sendo o mesmo procedimento realizado até o último poço. Ao final, foi possível obter quantidade suficiente de RNA total para realização de todos os experimentos envolvendo expressão gênica. As amostras foram mantidas à TA durante 15 min e armazenadas no freezer $-20{ }^{\circ} \mathrm{C}$ por, no mínimo, 24 h. Decorrido este período, para cada $1 \mathrm{~mL}$ do reagente Trizol (Gibco) foram adicionados $200 \mu \mathrm{L}$ de clorofórmio (Merck). Os tubos foram vigorosamente agitados por $30 \mathrm{~s}$ e mantidos no gelo durante $5 \mathrm{~min}$. A seguir, os tubos foram centrifugados a $12000 \mathrm{~g}$ por $15 \mathrm{~min}$ a $4{ }^{\circ} \mathrm{C}$ e a fase aquosa formada (superior), coletada em novos tubos de $2 \mathrm{~mL}$ (Eppendorf AG, Hamburg, Alemanha). Em seguida, foram adicionados $250 \mu \mathrm{L}$ de etanol a 96\% (Merck) às amostras e as mesmas, centrifugadas em colunas de sílica gel presentes no kit de extração SV Total RNA Isolation System (Promega, Madison, WI, EUA), no qual uma das etapas do processo de extração envolve o tratamento com DNAse, de acordo com as recomendações fornecidas pelo fabricante.

A concentração e pureza do RNA total foram avaliadas por espectrofotometria em aparelho NanoVue (GE Healthcare, EUA). A leitura foi realizada nos comprimentos de onda de $260 \mathrm{~nm}, 280 \mathrm{~nm}$ e $230 \mathrm{~nm}$, para obtenção da concentração de RNA/ $\mu \mathrm{L}$ e avaliar a contaminação por proteínas e fenol, respectivamente.

O cDNA foi sintetizado a partir de $1 \mu \mathrm{g}$ de RNA total utilizando o kit $R T^{2}$ First Strand (SuperArray, EUA), de acordo com as instruções do fabricante. Brevemente, foram adicionados em tubo Eppendorf: $1 \mu \mathrm{g}$ de RNA total e $2 \mu \mathrm{L}$ do tampão GE (10X), para um volume final de $10 \mu \mathrm{L} /$ reação. Essa amostra foi incubada em 
termociclador Master Cycler Gradiente (Eppendorf AG) a $42{ }^{\circ} \mathrm{C}$ por 5 min e resfriada a $4{ }^{\circ} \mathrm{C}$ por 2 min. Em seguida foi adicionado um coquetel contendo: $4 \mu \mathrm{L}$ do tampão $\mathrm{BC} 3,1 \mu \mathrm{L}$ do primer $\mathrm{P} 2,2 \mu \mathrm{L}$ da enzima RE3 e $3 \mu \mathrm{L}$ de água RNase Free. A amostra foi, novamente, incubada no termociclador a $42^{\circ} \mathrm{C}$ por $15 \mathrm{~min}, 95^{\circ} \mathrm{C}$ por $5 \mathrm{~min}$, seguido pelo resfriamento a $4^{\circ} \mathrm{C}$. Na sequência, foram adicionados $91 \mu \mathrm{L}$ de água deionizada estéril e o cDNA diluído foi estocado em freezer $-20^{\circ} \mathrm{C}$.

\subsubsection{Método de PCR Array}

A técnica PCR Array permite a análise simultânea de 84 genes envolvidos em vias específicas de sinalização, utilizando o aparelho CFX96 (BioRad, Hercules, CA, EUA). Uma das vantagens desta metodologia é a análise da expressão de vários genes em um único experimento. Para a reação de PCR Array, foram adicionados em um tubo Falcon: $1350 \mu \mathrm{L}$ do tampão 2X SuperArray $R T^{2}$ qPCR Master Mix; 102 $\mu \mathrm{L}$ de reação de síntese de cDNA diluído 5,6 vezes e $1248 \mu \mathrm{L}$ de água deionizada. Foram adicionados $25 \mu \mathrm{L}$ desta mistura em cada poço da placa já contendo pares de primers liofilizados. Em seguida, a reação de Real time PCR foi executada no aparelho CFX96 e os cálculos, realizados pelo Software $R T^{2}$ Profiler PCR Arrat Data Analysis (SuperArray). Genes apresentando valores de ciclo treshold (Ct, na sigla em inglês) acima de 35 foram considerados não expressos. A Tabela 1 relaciona os genes presentes na placa de PCR Array para osteogênese de camundongo. 
Tabela 1. Relação de genes para camundongo na placa de PCR Array (SuperArray)

\begin{tabular}{|c|c|c|c|}
\hline Posição & Número/Acesso & Símbolo & Descrição \\
\hline $\mathrm{A} 01$ & NM_013465 & Ahsg & Alpha-2-HS-glycoprotein \\
\hline $\mathrm{A} 02$ & NM_007431 & Alpl & Alkaline phosphatase, liver/bone/kidney \\
\hline A03 & NM_009664 & Ambn & Ameloblastin \\
\hline $\mathrm{A} 04$ & NM_009673 & Anxa5 & Annexin A5 \\
\hline A05 & NM_007542 & Bgn & Biglycan \\
\hline A06 & NM_009755 & Bmp1 & Bone morphogenetic protein 1 \\
\hline $\mathrm{A} 07$ & NM_007553 & Bmp2 & Bone morphogenetic protein 2 \\
\hline A08 & NM_173404 & Bmp3 & Bone morphogenetic protein 3 \\
\hline A09 & NM_007554 & Bmp4 & Bone morphogenetic protein 4 \\
\hline A10 & NM_007555 & Bmp5 & Bone morphogenetic protein 5 \\
\hline A11 & NM_007556 & Bmp6 & Bone morphogenetic protein 6 \\
\hline A12 & NM_009758 & Bmpr1a & Bone morphogenetic protein receptor, type $1 \mathrm{~A}$ \\
\hline B01 & NM_007560 & Bmpr1b & Bone morphogenetic protein receptor, type 1B \\
\hline B02 & NM_007643 & Cd36 & CD36 antigen \\
\hline B03 & NM_009866 & Cdh11 & Cadherin 11 \\
\hline B04 & NM_009925 & Col10a1 & Collagen, type X, alpha 1 \\
\hline B05 & NM_007729 & Col11a1 & Collagen, type XI, alpha 1 \\
\hline B06 & NM_007730 & Col12a1 & Collagen, type XII, alpha 1 \\
\hline B07 & NM_181277 & Col14a1 & Collagen, type XIV, alpha 1 \\
\hline B08 & NM_007742 & Col1a1 & Collagen, type I, alpha 1 \\
\hline B09 & NM_007743 & Col1a2 & Collagen, type I, alpha 2 \\
\hline $\mathrm{B} 10$ & NM_031163 & Col2a1 & Collagen, type II, alpha 1 \\
\hline $\mathrm{B} 11$ & NM_009930 & Col3a1 & Collagen, type III, alpha 1 \\
\hline $\mathrm{B} 12$ & NM_009931 & Col4a1 & Collagen, type IV, alpha 1 \\
\hline $\mathrm{C} 01$ & NM_009932 & Col4a2 & Collagen, type IV, alpha 2 \\
\hline $\mathrm{C} 02$ & NM_015734 & Col5a1 & Collagen, type $\mathrm{V}$, alpha 1 \\
\hline $\mathrm{C03}$ & NM_009933 & Col6a1 & Collagen, type VI, alpha 1 \\
\hline $\mathrm{C04}$ & NM_146007 & Col6a2 & Collagen, type $\mathrm{VI}$, alpha 2 \\
\hline $\mathrm{C} 05$ & NM_007738 & Col7a1 & Collagen, type VII, alpha 1 \\
\hline $\mathrm{C} 06$ & NM_016685 & Comp & Cartilage oligomeric matrix protein \\
\hline $\mathrm{C} 07$ & NM_009969 & Csf2 & Colony stimulating factor 2 (granulocyte-macrophage) \\
\hline $\mathrm{C08}$ & NM_009971 & Csf3 & Colony stimulating factor 3 (granulocyte) \\
\hline $\mathrm{C} 09$ & NM_007802 & Ctsk & Cathepsin K \\
\hline C10 & NM_016779 & Dmp1 & Dentin matrix protein 1 \\
\hline C11 & NM_010113 & Egf & Epidermal growth factor \\
\hline C12 & NM_017468 & Enam & Enamelin \\
\hline D01 & NM_010197 & Fgf1 & Fibroblast growth factor 1 \\
\hline $\mathrm{D} 02$ & NM_008006 & Fgf2 & Fibroblast growth factor 2 \\
\hline D03 & NM_008007 & Fgf3 & Fibroblast growth factor 3 \\
\hline D04 & NM_010206 & Fgfr1 & Fibroblast growth factor receptor 1 \\
\hline D05 & NM_010207 & Fgfr2 & Fibroblast growth factor receptor 2 \\
\hline D06 & NM_010228 & Flt1 & FMS-like tyrosine kinase 1 \\
\hline D07 & NM_010233 & Fn1 & Fibronectin 1 \\
\hline D08 & NM_145741 & Gdf10 & Growth differentiation factor 10 \\
\hline D09 & NM_010493 & Icam1 & Intercellular adhesion molecule 1 \\
\hline D10 & NM_010512 & Igf1 & Insulin-like growth factor 1 \\
\hline D11 & NM_010513 & $\operatorname{lgg} 1 \mathrm{r}$ & Insulin-like growth factor I receptor \\
\hline $\mathrm{D} 12$ & NM_008396 & $\operatorname{Itga2}$ & Integrin alpha 2 \\
\hline E01 & NM_010575 & Itga2b & Integrin alpha $2 \mathrm{~b}$ \\
\hline
\end{tabular}




\begin{tabular}{|c|c|c|c|}
\hline Posição & NúmerolAcesso & Símbolo & Descrição \\
\hline E02 & NM_013565 & Itga3 & Integrin alpha 3 \\
\hline E03 & NM_008401 & Itgam & Integrin alpha $\mathrm{M}$ \\
\hline E04 & NM_008402 & Itgav & Integrin alpha $\mathrm{V}$ \\
\hline E05 & NM_010578 & $\operatorname{ltgb} 1$ & Integrin beta 1 (fibronectin receptor beta) \\
\hline E06 & NM_019471 & Mmp10 & Matrix metallopeptidase 10 \\
\hline E07 & NM_008610 & Mmp2 & Matrix metallopeptidase 2 \\
\hline E08 & NM_008611 & Mmp8 & Matrix metallopeptidase 8 \\
\hline E09 & NM_013599 & Mmp9 & Matrix metallopeptidase 9 \\
\hline E10 & NM_010835 & Msx1 & Homeobox, msh-like 1 \\
\hline E11 & NM_008689 & Nfkb1 & $\begin{array}{c}\text { Nuclear factor of kappa light polypeptide gene enhancer } \\
\text { in B-cells } 1, \text { p105 }\end{array}$ \\
\hline E12 & NM_008808 & Pdgfa & Platelet derived growth factor, alpha \\
\hline F01 & NM_011077 & Phex & $\begin{array}{l}\text { Phosphate regulating gene with homologies to } \\
\text { endopeptidases on the } \mathrm{X} \text { chromosome } \\
\text { (hypophosphatemia, vitamin D resistant rickets) }\end{array}$ \\
\hline F02 & NM_009820 & Runx2 & Runt related transcription factor 2 \\
\hline F03 & NM_016741 & Scarb1 & Scavenger receptor class $B$, member 1 \\
\hline F04 & NM_009825 & Serpinh1 & Serine (cysteine) peptidase inhibitor, clade $\mathrm{H}$, member 1 \\
\hline F05 & NM_008539 & Smad1 & MAD homolog 1 (Drosophila) \\
\hline F06 & NM_010754 & Smad2 & MAD homolog 2 (Drosophila) \\
\hline F07 & NM_016769 & Smad3 & MAD homolog 3 (Drosophila) \\
\hline F08 & NM_008540 & Smad4 & MAD homolog 4 (Drosophila) \\
\hline F09 & NM_024449 & Sost & Sclerostin \\
\hline F10 & NM_011448 & Sox9 & SRY-box containing gene 9 \\
\hline F11 & NM_018783 & Tfip11 & Tuftelin interacting protein 11 \\
\hline F12 & NM_011577 & Tgfb1 & Transforming growth factor, beta 1 \\
\hline G01 & NM_009367 & Tgfb2 & Transforming growth factor, beta 2 \\
\hline G02 & NM_009368 & Tgfb3 & Transforming growth factor, beta 3 \\
\hline G03 & NM_009370 & Tgfbr1 & Transforming growth factor, beta receptor I \\
\hline G04 & NM_009371 & Tgfbr2 & Transforming growth factor, beta receptor II \\
\hline G05 & NM_011578 & Tgfbr3 & Transforming growth factor, beta receptor III \\
\hline G06 & NM_013693 & Tnf & Tumor necrosis factor \\
\hline G07 & NM_011656 & Tuft1 & Tuftelin 1 \\
\hline G08 & NM_011658 & Twist1 & Twist homolog 1 (Drosophila) \\
\hline G09 & NM_011693 & Vcam1 & Vascular cell adhesion molecule 1 \\
\hline G10 & NM_009504 & $\mathrm{Vdr}$ & Vitamin D receptor \\
\hline G11 & NM_009505 & Vegfa & Vascular endothelial growth factor $A$ \\
\hline G12 & NM_011697 & Vegfb & Vascular endothelial growth factor B \\
\hline $\mathrm{H} 01$ & NM_010368 & Gusb & Glucuronidase, beta \\
\hline $\mathrm{H} 02$ & NM_013556 & Hprt1 & Hypoxanthine guanine phosphoribosyl transferase 1 \\
\hline $\mathrm{HO3}$ & NM_008302 & Hsp90ab1 & Heat shock protein $90 \alpha$ (cytosolic), class B member 1 \\
\hline $\mathrm{H} 04$ & NM_008084 & Gapdh & Glyceraldehyde-3-phosphate dehydrogenase \\
\hline $\mathrm{H} 05$ & NM_007393 & Actb & Actin, beta \\
\hline $\mathrm{H} 06$ & SA_00106 & MGDC & Mouse Genomic DNA Contamination \\
\hline $\mathrm{H} 07$ & SA_00104 & RTC & Reverse Transcription Control \\
\hline $\mathrm{H} 08$ & SA_00104 & RTC & Reverse Transcription Control \\
\hline $\mathrm{H} 09$ & SA_00104 & RTC & Reverse Transcription Control \\
\hline $\mathrm{H} 10$ & SA_00103 & PPC & Positive PCR Control \\
\hline $\mathrm{H} 11$ & SA_00103 & PPC & Positive PCR Control \\
\hline $\mathrm{H} 12$ & SA_00103 & PPC & Positive PCR Control \\
\hline
\end{tabular}


A normalização e quantificação relativa da expressão gênica foram realizadas pelo método de $2^{-\triangle \Delta C T}$ (LIVAK; SCHMITTGEN, 2001). Usando esse método, os dados foram representados como diferença (em vezes) na expressão gênica, que foi normalizada pelo gene endógeno de camundongo beta-actina (ACTB) e relativa ao controle bioinerte (Boro) ou ao bioativo (45S5).

\subsubsection{Análise dos resultados}

A significância estatística das diferenças de expressão gênica foi obtida por meio do Software RT2 Profiler PCR Arrat Data Analysis (SuperArray). Valores de Ct (Ciclo Treshold) foram fornecidos ao software para o cálculo da regulação da expressão gênica, assim como a obtenção dos valores estatisticamente significantes $(p \leq 0,05)$. O software realizou o teste t entre o grupo controle (bioinerte ou bioativo) e cada grupo experimental, sendo os valores posteriormente submetidos ao teste de correção de Benjamini-Hochberg. Os experimentos foram realizados em triplicata. Valores de $p \leq 0,05$ foram considerados estatisticamente significantes. 


\section{RESULTADOS}

\subsection{Morfologia celular, imunolocalização de BSP e atividade de fosfatase alcalina in situ (Fast red)}

As marcações por fluorescência direta do citoesqueleto de actina e núcleo revelaram confluência das culturas de células MC3T3-E1 sobre as superfícies de vidros e vitrocerâmicas em 7, 12 e 21 dias, com progressiva formação de multicamadas celulares (Figura 1). Aumento mais evidente na densidade de núcleos celulares ocorria entre o $7^{\circ}$ e o $12^{\circ}$ dia (Figura 1, fluorescência azul; comparem-se E-H com A-D). Para todas as culturas e nos 3 tempos, predominava o padrão de marcação de actina de fibras de estresse, distribuídas em diferentes direções e por todo o citoplasma; exceção para as células sobre os materiais bioativos em 7 dias, que exibiam áreas circulares destituídas de marcação, por vezes bem delimitadas, correspondentes a acúmulos sobre as células de material resultante das superfícies reativas (dados não mostrados). Esse fenômeno era mais pronunciado sobre as duas preparações de Biosilicato ${ }^{\circledR}$ (Figura 1, fluorescência verde; comparem-se C e D com B). Divisões mitóticas foram observadas em todos os grupos e nos 3 tempos, predominantes em 7 dias.

A marcação para BSP mostrou padrão puntiforme discreto por toda a cultura, por vezes visivelmente citoplasmática, adjacente ao núcleo, tendendo a uma maior intensidade nos materiais bioativos e nos tempos de 12 e 21 dias (Figura 1, fluorescência vermelha).

Imagens macroscópicas das culturas marcadas com Fast red revelaram, para os 4 materiais avaliados, progressivo aumento de atividade de fosfatase alcalina in situ, de 7 para 21 dias (Figura 1A-L, destaques). 

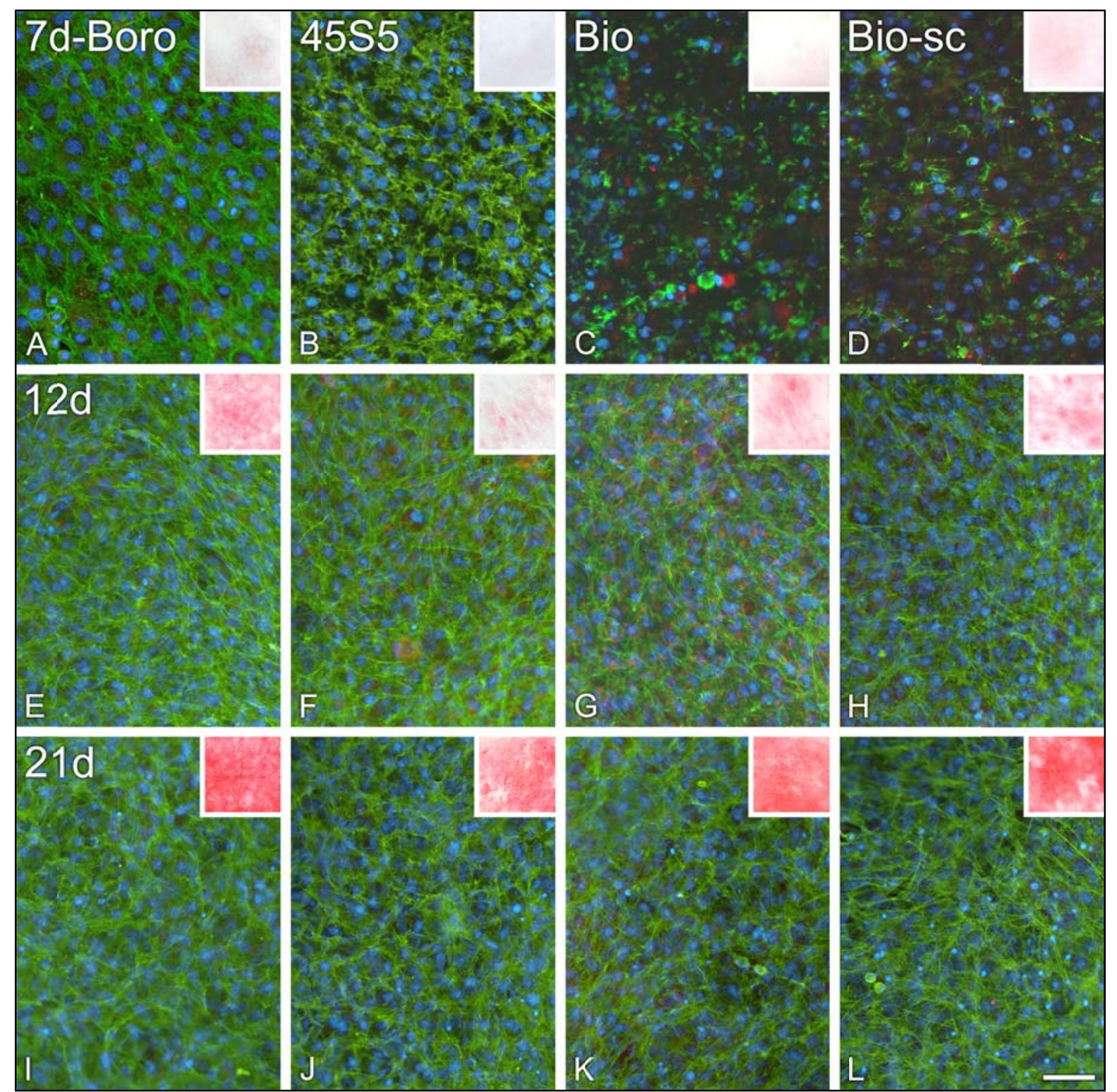

Figura 1. Epifluorescência de culturas de células MC3T3-E1 crescidas sobre borosilicato (Boro, $\mathrm{A}, \mathrm{E}, \mathrm{I})$, Bioglass ${ }^{\circledR} 45 \mathrm{~S} 5(45 \mathrm{~S} 5, \mathrm{~B}, \mathrm{~F}, \mathrm{~J})$, Biosilicato ${ }^{\circledR}$ (Bio, C,G,K) e Biosilicato ${ }^{\circledR}$ para scaffold (Bio-sc, $D, H, L)$, em 7 (A-D), $12(E-H)$ e 21 (I-L) dias. Destaques em A-L representam imagens macroscópicas das culturas marcadas com Fast red. (A-L) Fluorescências verde, vermelha e azul revelam, respectivamente, citoesqueleto de actina, localização de BSP e núcleos celulares. Notem-se culturas confluentes já em 7 dias (A-D), com áreas de ausência de marcação para actina nas células MC3T3E1 sobre os materiais bioativos. O aumento da população celular é mais evidente de 7 para 12 dias sobre todos os materiais (comparem-se E-H com A-D). Marcação por Fast red é progressivamente mais intensa para todos os grupos de 7 a 21 dias (comparem-se destaques em I-L com destaques em E-H e A-D). A barra de escala representa para A-L $100 \mu \mathrm{m}$ e para os destaques em A-L, $6 \mathrm{~mm}$. 


\subsection{Mineralização}

Em 21 dias, macroscopicamente, a coloração com ARS revelou culturas mais intensamente coradas sobre os materiais bioativos. A quantificação de ARS mostrou significância estatística para os valores de absorbância $(p<0,01)$, com Boro $<45 S 5$ $<$ Bio < Bio-sc (Figura 2).

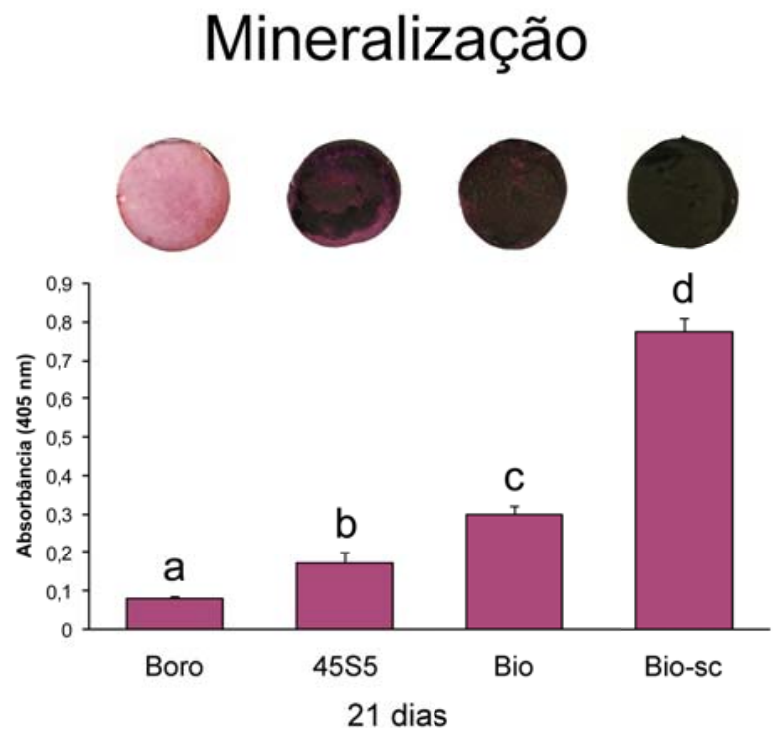

Figura 2. Aspectos macroscópicos de culturas de células MC3T3-E1 sobre borosilicato (Boro), Bioglass $^{\circledR} 45 S 5$ (45S5), Biosilicato ${ }^{\circledR}$ (Bio) e Biosilicato ${ }^{\circledR}$ para scaffold (Bio-sc), coradas com vermelho de Alizarina (ARS), e quantificação de ARS, indicando o maior potencial osteogênico de culturas sobre Bio-sc. Barras com letras diferentes indicam diferenças estatisticamente significantes entre os grupos. 


\subsection{Análise da expressão gênica}

Os resultados mostraram expressão diferencial de genes relacionados à osteogênese para os 3 tempos de progressão das culturas de células MC3T3-E1 sobre os materiais vítreo (45S5) e vitrocerâmicos (Bio e Bio-sc) bioativos em comparação ao Boro, bioinerte (Tabelas 2 a 5), e sobre os materiais vitrocerâmicos em comparação ao 45S5 (Tabelas 6 a 9).

Na comparação com o borosilicato, enquanto que células MC3T3-E1 sobre 45 S5 mostraram maior número de genes dos diferentes grupos sobre-expressos em 7 e 21 dias e reprimidos em 12 dias, células sobre Bio e Bio-sc exibiam maior número de genes sobre-expressos em 12 e 21 dias e reprimidos em 7 dias (Tabela 5).

Quando se compararam as duas preparações de Biosilicato ${ }^{\circledR}$ ao $45 \mathrm{~S} 5$, notouse que a sobre-expressão de genes ocorria, predominantemente, aos 12 dias, e apenas aos 21 dias para o Bio-sc. A repressão de genes predominou em 7 dias, em maior número para o Bio (Tabela 9). 
Tabela 2. Expressão gênica por PCR Array de células MC3T3-E1 (sub-clone 14) cultivadas por 7 dias sobre borosilicato, Bioglass ${ }^{\circledR} 45 S 5$ (45S5), Biosilicato ${ }^{\circledR}$ (Bio) e Biosilicato ${ }^{\circledR}$ para scaffold (Bio-sc). Os valores de expressão relativa foram normalizados pelo gene constitutivo beta-actina (ACTB) e calibrados em relação ao controle bioinerte borosilicato. Com cut-off de 1,5 e p<0,05 utilizando a correção de Benjamin-Hochberg, valores positivos indicam aumento e valores negativos, diminuição da expressão de cada gene avaliado. O traço indica que não houve alteração na expressão gênica

\begin{tabular}{|c|c|c|c|c|}
\hline \multirow{2}{*}{ Símbolo } & \multirow{2}{*}{ Descrição } & \multicolumn{3}{|c|}{ Expressão Relativa (fold) - 7dias } \\
\hline & & $45 S 5$ & Bio & Bio-sc \\
\hline \multicolumn{5}{|c|}{ Proteínas não colágenas da matriz óssea } \\
\hline Alpl & Alkaline phosphatase, liver/bone/kidney & - & - & $-1,82$ \\
\hline Bgn & Biglycan & 1,62 & 1,87 & - \\
\hline Dmp1 & Dentin matrix acidic phosphoprotein 1 & 29,09 & 9,54 & 6,94 \\
\hline Fn1 & Fibronectin 1 & 2,08 & 2,84 & 2,19 \\
\hline Ahsg & Alpha-2-HS-glycoprotein & 5,51 & - & 2,06 \\
\hline \multicolumn{5}{|c|}{ Superfamília das proteínas morfogenéticas ósseas } \\
\hline Bmp1 & Bone morphogenetic protein 1 & - & $-1,70$ & $-1,53$ \\
\hline Bmp2 & Bone morphogenetic protein 2 & - & - & - \\
\hline Bmp3 & Bone morphogenetic protein 3 & - & 1,78 & - \\
\hline Bmp4 & Bone morphogenetic protein 4 & 1,69 & - & - \\
\hline Bmp5 & Bone morphogenetic protein 5 & 2,19 & 2,35 & - \\
\hline Bmp6 & Bone morphogenetic protein 6 & - & - & - \\
\hline Gdf10 & Growth differentiation factor 10 & 2,05 & 1,93 & - \\
\hline Tgfb1 & Transforming growth factor, beta 1 & - & 1,94 & - \\
\hline Tgfb2 & Transforming growth factor, beta 2 & 1,62 & - & - \\
\hline Tgfb3 & Transforming growth factor, beta 3 & 1,65 & 1,85 & - \\
\hline \multicolumn{5}{|l|}{ Receptores } \\
\hline Cd36 & CD36 molecule & - & - & - \\
\hline Cdh11 & Cadherin 11 & 2,12 & $-3,46$ & 1,97 \\
\hline Fgfr1 & Fibroblast growth factor receptor 1 & 2,19 & - & - \\
\hline Fgfr2 & Fibroblast growth factor receptor 2 & - & $-2,37$ & - \\
\hline Flt1 & Fms-like tyrosine kinase 1 & - & - & - \\
\hline Icam1 & Intercellular adhesion molecule 1 & 2,32 & - & - \\
\hline Scarb1 & Scavenger receptor class $B$, member 1 & - & 1,71 & - \\
\hline Tgfbr1 & Transforming growth factor, beta receptor I & 2,17 & 1,52 & - \\
\hline Tgfbr2 & Transforming growth factor, beta receptor II & 1,68 & 4,04 & 1,52 \\
\hline Tgfbr3 & Transforming growth factor, beta receptor III & 2,96 & 1,73 & - \\
\hline Vcam1 & Vascular cell adhesion molecule 1 & 2,55 & - & - \\
\hline$V d r$ & Vitamin D receptor & $-1,71$ & $-6,49$ & $-1,61$ \\
\hline Igf1r & Insulin-like growth factor 1 receptor & - & - & $-1,55$ \\
\hline Phex & Phosphate regulating endopeptidase homolog, $X$-linked & 11,46 & 2,59 & 5,64 \\
\hline Bmpr1a & Bone morphogenetic protein receptor, type $1 \mathrm{~A}$ & 4,30 & - & 1,88 \\
\hline Bmpr1b & Bone morphogenetic protein receptor, type $1 B$ & 2,02 & - & - \\
\hline \multicolumn{5}{|c|}{ Fatores de crescimento } \\
\hline Egf & Epidermal growth factor & 3,03 & - & - \\
\hline Fgf1 & Fibroblast growth factor 1 & - & - & - \\
\hline Fgf2 & Fibroblast growth factor 2 & 2,80 & - & - \\
\hline Fgf3 & Fibroblast growth factor 3 & 2,32 & - & - \\
\hline Igf1 & Insulin-like growth factor 1 & - & $-3,20$ & - \\
\hline Pdgfa & Platelet derived growth factor, alpha & - & $-1,87$ & $-1,94$ \\
\hline Vegfa & Vascular endothelial growth factor $A$ & - & - & - \\
\hline Vegfb & Vascular endothelial growth factor $B$ & 1,80 & 2,76 & - \\
\hline Csf2 & Colony stimulating factor 2 (granulocyte-macrophage) & - & - & - \\
\hline Csf3 & Colony stimulating factor 3 (granulocyte) & - & - & - \\
\hline
\end{tabular}




\begin{tabular}{|c|c|c|c|c|}
\hline \multirow{2}{*}{ Símbolo } & \multirow{2}{*}{ Descrição } & \multicolumn{3}{|c|}{ Expressão Relativa (fold) - 7dias } \\
\hline & & $45 S 5$ & Bio & Bio-sc \\
\hline Itga2 & Integrin alpha 2 & 1,75 & - & - \\
\hline $\operatorname{ltga} 2 b$ & Integrin alpha $2 b$ & - & - & - \\
\hline $\operatorname{ltga3}$ & Integrin alpha 3 & 2,24 & 3,83 & - \\
\hline Itgam & Integrin alpha $M$ & 1,56 & 1,69 & - \\
\hline Itgav & Integrin alpha $\mathrm{V}$ & 2,71 & - & - \\
\hline $\operatorname{ltg} 1$ & Integrin beta 1 (fibronectin receptor beta) & 1,91 & 1,57 & - \\
\hline \multicolumn{5}{|l|}{ Colágeno } \\
\hline Col10a1 & Collagen, type $X$, alpha 1 & 8,63 & 4,89 & 3,78 \\
\hline Col11a1 & Collagen, type XI, alpha 1 & - & $-7,19$ & - \\
\hline Col12a1 & Collagen, type XII, alpha 1 & 1,54 & $-1,56$ & - \\
\hline Col14a1 & Collagen, type XIV, alpha 1 & 1,53 & 2,21 & - \\
\hline Col1a1 & Collagen, type I, alpha 1 & - & 1,86 & - \\
\hline Col1a2 & Collagen, type I, alpha 2 & - & $-3,61$ & $-1,70$ \\
\hline Col2a1 & Collagen, type II, alpha 1 & $-2,75$ & $-4,26$ & $-3,12$ \\
\hline Col3a1 & Collagen, type III, alpha 1 & - & $-2,06$ & $-1,80$ \\
\hline Col4a1 & Collagen, type IV, alpha 1 & 5,40 & 5,79 & 5,75 \\
\hline Col4a2 & Collagen, type IV, alpha 2 & 2,20 & 2,01 & 1,66 \\
\hline Col5a1 & Collagen, type $V$, alpha 1 & - & - & - \\
\hline Col6a1 & Collagen, type VI, alpha 1 & - & - & - \\
\hline Col6a2 & Collagen, type VI, alpha 2 & - & 1,85 & - \\
\hline Col7a1 & Collagen, type VII, alpha 1 & 1,70 & 1,61 & - \\
\hline \multicolumn{5}{|c|}{ Genes relacionados à cartilagem } \\
\hline Comp & Cartilage oligomeric matrix protein & 2,29 & - & - \\
\hline Sox9 & SRY - box containing gene 9 & - & $-1,62$ & - \\
\hline \multicolumn{5}{|c|}{ Metaloproteinases } \\
\hline Mmp10 & Matrix metallopeptidase 10 & - & - & - \\
\hline Mmp2 & Matrix metallopeptidase 2 & - & $-1,52$ & $-1,63$ \\
\hline Mmp8 & Matrix metallopeptidase 8 & 2,09 & - & - \\
\hline Mmp9 & Matrix metallopeptidase 9 & $-2,06$ & - & - \\
\hline \multicolumn{5}{|c|}{ Fatores de Transcrição } \\
\hline Ms $x 1$ & Homeobox,msh-like 1 & - & $-5,43$ & - \\
\hline Nfkb1 & Nuclear factor of kappa in B-cells 1, p105 & - & - & - \\
\hline Runx2 & Runt related transcription factor 2 & - & - & - \\
\hline Smad1 & MAD homolog 1 (Drosophila) & - & $-3,92$ & - \\
\hline Smad2 & MAD homolog 2 (Drosophila) & 1,57 & $-2,09$ & - \\
\hline Smad3 & MAD homolog 3 (Drosophila) & - & 1,68 & - \\
\hline Smad4 & MAD homolog 4 (Drosophila) & - & - & - \\
\hline Twist1 & Twist homolog 1 (Drosophila) & 1,50 & $-1,60$ & - \\
\hline \multicolumn{5}{|l|}{ Outros genes } \\
\hline Ctsk & Cathepsin K & - & - & - \\
\hline Serpinh1 & Serine (or cysteine) peptidase inhibitor, clade $H$, member 1 & - & 1,94 & - \\
\hline Tuft1 & Tuftelin 1 & - & - & - \\
\hline Tfip11 & Tuftelin interacting protein 11 & - & $-1,74$ & - \\
\hline Anxa5 & Annexin A5 & - & 2,19 & - \\
\hline Ambn & Ameloblastin & 1,52 & - & - \\
\hline Enam & Enamelin & - & - & - \\
\hline Sost & Sclerostin & 1,95 & - & $-1,64$ \\
\hline Tnf & Tumor necrosis factor & - & - & - \\
\hline
\end{tabular}


Tabela 3. Expressão gênica por PCR Array de células MC3T3-E1 (sub-clone 14) cultivadas por 12 dias sobre borosilicato, Bioglass ${ }^{\circledR} 45 S 5$ (45S5), Biosilicato ${ }^{\circledR}$ (Bio) e Biosilicato ${ }^{\circledR}$ para scaffold (Bio-sc). Os valores de expressão relativa foram normalizados pelo gene constitutivo beta-actina (ACTB) e calibrados em relação ao controle bioinerte borosilicato. Com cut-off de 1,5 e p<0,05 utilizando a correção de Benjamin-Hochberg, valores positivos indicam aumento e valores negativos, diminuição da expressão de cada gene avaliado. O traço indica que não houve alteração na expressão gênica

\begin{tabular}{|c|c|c|c|c|}
\hline \multirow{2}{*}{ Símbolo } & \multirow{2}{*}{ Descrição } & \multicolumn{3}{|c|}{ Expressão Relativa (fold) - 12 dias } \\
\hline & & $45 \mathrm{~S} 5$ & Bio & Bio-sc \\
\hline \multicolumn{5}{|c|}{ Proteínas não colágenas da matriz óssea } \\
\hline Alpl & Alkaline phosphatase, liver/bone/kidney & - & - & - \\
\hline Bgn & Biglycan & $-1,70$ & - & - \\
\hline Dmp1 & Dentin matrix acidic phosphoprotein 1 & 2,62 & 2,30 & 5,34 \\
\hline Fn1 & Fibronectin 1 & $-1,88$ & 3,00 & - \\
\hline Ahsg & Alpha-2-HS-glycoprotein & - & 7,11 & 7,10 \\
\hline \multicolumn{5}{|c|}{ Superfamília das proteínas morfogenéticas ósseas } \\
\hline Bmp1 & Bone morphogenetic protein 1 & $-2,07$ & - & - \\
\hline Bmp2 & Bone morphogenetic protein 2 & - & - & - \\
\hline Bmp3 & Bone morphogenetic protein 3 & - & 1,56 & - \\
\hline Bmp4 & Bone morphogenetic protein 4 & - & - & - \\
\hline Bmp5 & Bone morphogenetic protein 5 & 1,63 & - & 1,97 \\
\hline Bmp6 & Bone morphogenetic protein 6 & - & - & - \\
\hline Gdf10 & Growth differentiation factor 10 & - & 1,98 & 1,81 \\
\hline $\operatorname{Tgfb1}$ & Transforming growth factor, beta 1 & - & - & - \\
\hline Tgfb2 & Transforming growth factor, beta 2 & $-1,92$ & 1,78 & - \\
\hline Tgfb3 & Transforming growth factor, beta 3 & - & - & - \\
\hline \multicolumn{5}{|l|}{ Receptores } \\
\hline Cd36 & CD36 molecule & - & $-1,86$ & - \\
\hline Cdh11 & Cadherin 11 & - & 1,50 & 2,31 \\
\hline Fgfr1 & Fibroblast growth factor receptor 1 & - & 2,06 & 2,00 \\
\hline Fgfr2 & Fibroblast growth factor receptor 2 & $-1,63$ & - & - \\
\hline Flt1 & Fms-like tyrosine kinase 1 & - & 1,78 & - \\
\hline Icam1 & Intercellular adhesion molecule 1 & - & - & - \\
\hline Scarb1 & Scavenger receptor class $B$, member 1 & - & - & - \\
\hline Tgfbr1 & Transforming growth factor, beta receptor I & - & 1,69 & - \\
\hline Tgfbr2 & Transforming growth factor, beta receptor II & - & 2,30 & 1,59 \\
\hline Tgfbr3 & Transforming growth factor, beta receptor III & - & 1,97 & - \\
\hline Vcam1 & Vascular cell adhesion molecule 1 & - & 1,72 & 1,88 \\
\hline$V d r$ & Vitamin D receptor & $-2,50$ & - & - \\
\hline Igf1r & Insulin-like growth factor 1 receptor & - & 2,15 & - \\
\hline Phex & Phosphate regulating endopeptidase homolog, $X$-linked & $-3,69$ & - & - \\
\hline Bmpr1a & Bone morphogenetic protein receptor, type $1 \mathrm{~A}$ & $-2,73$ & - & - \\
\hline Bmpr1b & Bone morphogenetic protein receptor, type $1 B$ & - & 1,93 & - \\
\hline \multicolumn{5}{|c|}{ Fatores de crescimento } \\
\hline Egf & Epidermal growth factor & - & 2,45 & - \\
\hline Fgf1 & Fibroblast growth factor 1 & - & - & 1,59 \\
\hline Fgf2 & Fibroblast growth factor 2 & - & 2,64 & - \\
\hline Fgf3 & Fibroblast growth factor 3 & - & 1,50 & 1,72 \\
\hline lgf1 & Insulin-like growth factor 1 & $-1,91$ & - & - \\
\hline Pdgfa & Platelet derived growth factor, alpha & - & 1,62 & 1,81 \\
\hline Vegfa & Vascular endothelial growth factor $A$ & $-4,25$ & $-1,57$ & $-2,74$ \\
\hline Vegfb & Vascular endothelial growth factor $B$ & - & 1,53 & - \\
\hline Csf2 & Colony stimulating factor 2 (granulocyte-macrophage) & 1,69 & 1,50 & 2,52 \\
\hline Csf3 & Colony stimulating factor 3 (granulocyte) & - & - & - \\
\hline \multicolumn{5}{|c|}{ Receptores de integrina } \\
\hline
\end{tabular}




\begin{tabular}{|c|c|c|c|c|}
\hline \multirow{2}{*}{ Símbolo } & \multirow{2}{*}{ Descrição } & \multicolumn{3}{|c|}{ Expressão Relativa (fold) - 12 dias } \\
\hline & & $45 S 5$ & Bio & Bio-sc \\
\hline Itga2 & Integrin alpha 2 & - & 2,65 & - \\
\hline $\operatorname{ltga} 2 b$ & Integrin alpha $2 b$ & - & - & 4,90 \\
\hline Itga3 & Integrin alpha 3 & - & 2,16 & 1,55 \\
\hline Itgam & Integrin alpha $M$ & - & - & 1,93 \\
\hline Itgav & Integrin alpha $\mathrm{V}$ & $-3,08$ & 1,50 & $-1,70$ \\
\hline $\operatorname{ltg} 1$ & Integrin beta 1 (fibronectin receptor beta) & - & - & 1,63 \\
\hline \multicolumn{5}{|l|}{ Colágeno } \\
\hline Col10a1 & Collagen, type $X$, alpha 1 & 2,70 & 3,03 & 20,59 \\
\hline Col11a1 & Collagen, type XI, alpha 1 & $-4,33$ & - & - \\
\hline Col12a1 & Collagen, type XII, alpha 1 & $-2,27$ & 3,02 & $-1,52$ \\
\hline Col14a1 & Collagen, type XIV, alpha 1 & - & - & 1,74 \\
\hline Col1a1 & Collagen, type I, alpha 1 & $-2,07$ & 1,59 & $-1,98$ \\
\hline Col1a2 & Collagen, type I, alpha 2 & $-3,34$ & - & $-1,51$ \\
\hline Col2a1 & Collagen, type II, alpha 1 & $-2,71$ & - & - \\
\hline Col3a1 & Collagen, type III, alpha 1 & $-1,99$ & 1,98 & - \\
\hline Col4a1 & Collagen, type IV, alpha 1 & - & 3,85 & 1,79 \\
\hline Col4a2 & Collagen, type IV, alpha 2 & 1,76 & 2,26 & 2,33 \\
\hline Col5a1 & Collagen, type $V$, alpha 1 & $-2,37$ & - & $-1,72$ \\
\hline Col6a1 & Collagen, type VI, alpha 1 & - & 1,91 & 1,93 \\
\hline Col6a2 & Collagen, type VI, alpha 2 & - & 1,67 & - \\
\hline Col7a1 & Collagen, type VII, alpha 1 & - & - & - \\
\hline \multicolumn{5}{|c|}{ Genes relacionados à cartilagem } \\
\hline Comp & Cartilage oligomeric matrix protein & $-2,45$ & - & - \\
\hline Sox9 & SRY - box containing gene 9 & $-1,86$ & - & - \\
\hline \multicolumn{5}{|c|}{ Metaloproteinases } \\
\hline Mmp10 & Matrix metallopeptidase 10 & - & - & - \\
\hline Mmp2 & Matrix metallopeptidase 2 & - & 1,91 & 1,51 \\
\hline Mmp8 & Matrix metallopeptidase 8 & - & 1,90 & - \\
\hline Mmp9 & Matrix metallopeptidase 9 & - & 2,44 & 2,55 \\
\hline \multicolumn{5}{|c|}{ Fatores de Transcrição } \\
\hline Ms $\times 1$ & Homeobox,msh-like 1 & $-2,42$ & - & - \\
\hline Nfkb1 & Nuclear factor of kappa in B-cells 1, p105 & $-1,52$ & - & - \\
\hline Runx2 & Runt related transcription factor 2 & $-1,56$ & 2,24 & - \\
\hline Smad1 & MAD homolog 1 (Drosophila) & - & - & 1,67 \\
\hline Smad2 & MAD homolog 2 (Drosophila) & - & 1,70 & 1,61 \\
\hline Smad3 & MAD homolog 3 (Drosophila) & - & 1,62 & - \\
\hline Smad4 & MAD homolog 4 (Drosophila) & - & - & 2,32 \\
\hline Twist1 & Twist homolog 1 (Drosophila) & - & - & 2,02 \\
\hline \multicolumn{5}{|l|}{ Outros genes } \\
\hline Ctsk & Cathepsin K & - & - & 2,74 \\
\hline Serpinh1 & Serine (or cysteine) peptidase inhibitor, clade $\mathrm{H}$, member 1 & - & - & - \\
\hline Tuft1 & Tuftelin 1 & - & - & - \\
\hline Tfip11 & Tuftelin interacting protein 11 & - & - & 2,58 \\
\hline Anxa5 & Annexin A5 & - & - & 2,29 \\
\hline Ambn & Ameloblastin & $-1,88$ & 1,84 & - \\
\hline Enam & Enamelin & - & - & - \\
\hline Sost & Sclerostin & - & 1,73 & - \\
\hline Tnf & Tumor necrosis factor & - & - & - \\
\hline
\end{tabular}


Tabela 4. Expressão gênica por PCR Array de células MC3T3-E1 (sub-clone 14) cultivadas por 21 dias sobre borosilicato, Bioglass ${ }^{\circledR} 45 S 5$ (45S5), Biosilicato ${ }^{\circledR}$ (Bio) e Biosilicato ${ }^{\circledR}$ para scaffold (Bio-sc). Os valores de expressão relativa foram normalizados pelo gene constitutivo beta-actina (ACTB) e calibrados em relação ao controle bioinerte borosilicato. Com cut-off de 1,5 e p<0,05 utilizando a correção de Benjamin-Hochberg, valores positivos indicam aumento e valores negativos, diminuição da expressão de cada gene avaliado. O traço indica que não houve alteração na expressão gênica

\begin{tabular}{|c|c|c|c|c|}
\hline \multirow{2}{*}{ Símbolo } & \multirow{2}{*}{ Descrição } & \multicolumn{3}{|c|}{ Expressão Relativa (fold) - 21 dias } \\
\hline & & $45 S 5$ & Bio & Bio-sc \\
\hline \multicolumn{5}{|c|}{ Proteínas não colágenas da matriz óssea } \\
\hline Alpl & Alkaline phosphatase, liver/bone/kidney & - & - & - \\
\hline Bgn & Biglycan & - & - & - \\
\hline Dmp1 & Dentin matrix acidic phosphoprotein 1 & 8,65 & 7,17 & 2,58 \\
\hline Fn1 & Fibronectin 1 & 2,15 & 1,90 & 1,88 \\
\hline Ahsg & Alpha-2-HS-glycoprotein & - & - & - \\
\hline \multicolumn{5}{|c|}{ Superfamília das proteínas morfogenéticas ósseas } \\
\hline Bmp1 & Bone morphogenetic protein 1 & - & - & 1,64 \\
\hline Bmp2 & Bone morphogenetic protein 2 & - & - & - \\
\hline Bmp3 & Bone morphogenetic protein 3 & 1,98 & - & - \\
\hline Bmp4 & Bone morphogenetic protein 4 & 1,71 & - & 1,73 \\
\hline Bmp5 & Bone morphogenetic protein 5 & 2,13 & 1,71 & - \\
\hline Bmp6 & Bone morphogenetic protein 6 & - & - & - \\
\hline Gdf10 & Growth differentiation factor 10 & 1,53 & - & - \\
\hline Tgfb1 & Transforming growth factor, beta 1 & - & - & - \\
\hline Tgfb2 & Transforming growth factor, beta 2 & 1,78 & 1,88 & 2,53 \\
\hline Tgfb3 & Transforming growth factor, beta 3 & 1,57 & - & - \\
\hline \multicolumn{5}{|l|}{ Receptores } \\
\hline Cd36 & CD36 molecule & - & - & - \\
\hline Cdh11 & Cadherin 11 & 3,00 & 2,58 & 6,18 \\
\hline Fgfr1 & Fibroblast growth factor receptor 1 & 2,30 & 2,26 & 3,12 \\
\hline Fgfr2 & Fibroblast growth factor receptor 2 & 1,72 & - & 2,88 \\
\hline Flt1 & Fms-like tyrosine kinase 1 & 1,50 & - & - \\
\hline Icam1 & Intercellular adhesion molecule 1 & 1,67 & - & - \\
\hline Scarb1 & Scavenger receptor class $B$, member 1 & - & - & - \\
\hline Tgfbr1 & Transforming growth factor, beta receptor I & 2,14 & 1,52 & 1,87 \\
\hline Tgfbr2 & Transforming growth factor, beta receptor II & 1,62 & - & - \\
\hline Tgfbr3 & Transforming growth factor, beta receptor III & 2,11 & 1,68 & 1,85 \\
\hline Vcam1 & Vascular cell adhesion molecule 1 & 3,19 & 2,73 & 4,58 \\
\hline$V d r$ & Vitamin D receptor & - & - & 2,37 \\
\hline Igf1r & Insulin-like growth factor 1 receptor & 1,94 & - & 1,72 \\
\hline Phex & Phosphate regulating endopeptidase homolog, $X$-linked & - & - & 1,50 \\
\hline Bmpr1a & Bone morphogenetic protein receptor, type $1 A$ & 3,16 & 2,19 & 4,75 \\
\hline Bmpr1b & Bone morphogenetic protein receptor, type $1 B$ & 1,85 & - & - \\
\hline \multicolumn{5}{|c|}{ Fatores de crescimento } \\
\hline Egf & Epidermal growth factor & 2,14 & - & - \\
\hline Fgf1 & Fibroblast growth factor 1 & 1,54 & - & 2,83 \\
\hline Fgf2 & Fibroblast growth factor 2 & 1,94 & 2,75 & 2,75 \\
\hline Fgf3 & Fibroblast growth factor 3 & 1,83 & - & - \\
\hline $\operatorname{lgf1}$ & Insulin-like growth factor 1 & - & - & - \\
\hline Pdgfa & Platelet derived growth factor, alpha & - & 1,60 & 1,56 \\
\hline Vegfa & Vascular endothelial growth factor $A$ & - & - & - \\
\hline Vegfb & Vascular endothelial growth factor $B$ & 1,65 & - & - \\
\hline Csf2 & Colony stimulating factor 2 (granulocyte-macrophage) & 1,77 & - & - \\
\hline Csf3 & Colony stimulating factor 3 (granulocyte) & - & - & - \\
\hline Receptores de & grina & & & \\
\hline
\end{tabular}




\begin{tabular}{|c|c|c|c|c|}
\hline \multirow{2}{*}{ Símbolo } & \multirow{2}{*}{ Descrição } & \multicolumn{3}{|c|}{ Expressão Relativa (fold) - 21 dias } \\
\hline & & $45 S 5$ & Bio & Bio-sc \\
\hline $\operatorname{ltga2}$ & Integrin alpha 2 & 2,19 & 1,62 & 1,77 \\
\hline $\operatorname{ltga} 2 b$ & Integrin alpha $2 b$ & - & - & 2,49 \\
\hline $\operatorname{ltga3}$ & Integrin alpha 3 & 1,88 & - & 1,72 \\
\hline Itgam & Integrin alpha $M$ & 1,59 & - & - \\
\hline Itgav & Integrin alpha $V$ & 2,48 & 1,76 & 3,29 \\
\hline $\operatorname{ltg} 1$ & Integrin beta 1 (fibronectin receptor beta) & 2,08 & 1,65 & 2,12 \\
\hline \multicolumn{5}{|l|}{ Colágeno } \\
\hline Col10a1 & Collagen, type $X$, alpha 1 & 115,36 & 99,11 & 13,40 \\
\hline Col11a1 & Collagen, type XI, alpha 1 & 1,50 & - & 3,24 \\
\hline Col12a1 & Collagen, type XII, alpha 1 & 1,87 & 1,64 & 1,81 \\
\hline Col14a1 & Collagen, type XIV, alpha 1 & 1,97 & - & - \\
\hline Col1a1 & Collagen, type I, alpha 1 & - & $-1,50$ & - \\
\hline Col1a2 & Collagen, type I, alpha 2 & - & - & 1,77 \\
\hline Col2a1 & Collagen, type II, alpha 1 & 1,80 & - & 1,60 \\
\hline Col3a1 & Collagen, type III, alpha 1 & 1,75 & 1,57 & 2,58 \\
\hline Col4a1 & Collagen, type IV, alpha 1 & 4,48 & 4,38 & 3,70 \\
\hline Col4a2 & Collagen, type IV, alpha 2 & 2,71 & 2,38 & 2,78 \\
\hline Col5a1 & Collagen, type $V$, alpha 1 & 1,54 & - & 1,73 \\
\hline Col6a1 & Collagen, type VI, alpha 1 & 1,94 & 2,07 & 2,38 \\
\hline Col6a2 & Collagen, type VI, alpha 2 & - & - & - \\
\hline Col7a1 & Collagen, type VII, alpha 1 & - & - & - \\
\hline \multicolumn{5}{|c|}{ Genes relacionados à cartilagem } \\
\hline Comp & Cartilage oligomeric matrix protein & - & - & - \\
\hline Sox9 & SRY - box containing gene 9 & 1,63 & 1,65 & 1,62 \\
\hline \multicolumn{5}{|c|}{ Metaloproteinases } \\
\hline Mmp10 & Matrix metallopeptidase 10 & - & - & - \\
\hline Mmp2 & Matrix metallopeptidase 2 & 1,55 & 1,50 & 2,37 \\
\hline Mmp8 & Matrix metallopeptidase 8 & 1,73 & - & - \\
\hline Mmp9 & Matrix metallopeptidase 9 & - & - & 2,72 \\
\hline \multicolumn{5}{|c|}{ Fatores de Transcrição } \\
\hline Ms $\times 1$ & Homeobox,msh-like 1 & 1,70 & - & 4,13 \\
\hline Nfkb1 & Nuclear factor of kappa in B-cells 1, p105 & 2,38 & 1,96 & 2,47 \\
\hline Runx2 & Runt related transcription factor 2 & - & - & 1,82 \\
\hline Smad1 & MAD homolog 1 (Drosophila) & 1,57 & 1,68 & 3,98 \\
\hline Smad2 & MAD homolog 2 (Drosophila) & 2,34 & 2,02 & 3,14 \\
\hline Smad3 & MAD homolog 3 (Drosophila) & 1,76 & - & 1,98 \\
\hline Smad4 & MAD homolog 4 (Drosophila) & 1,79 & 1,65 & 1,80 \\
\hline Twist1 & Twist homolog 1 (Drosophila) & 2,13 & 1,72 & 3,05 \\
\hline \multicolumn{5}{|l|}{ Outros genes } \\
\hline Ctsk & Cathepsin K & 2,42 & 2,15 & 2,76 \\
\hline Serpinh1 & Serine (or cysteine) peptidase inhibitor, clade $H$, member 1 & - & - & - \\
\hline Tuft1 & Tuftelin 1 & 1,87 & - & 1,56 \\
\hline Tfip11 & Tuftelin interacting protein 11 & - & - & 1,98 \\
\hline Anxa5 & Annexin A5 & 1,54 & 1,65 & - \\
\hline$A m b n$ & Ameloblastin & - & $-1,65$ & - \\
\hline Enam & Enamelin & - & - & - \\
\hline Sost & Sclerostin & 1,78 & - & - \\
\hline Tnf & Tumor necrosis factor & - & - & - \\
\hline
\end{tabular}


Tabela 5. Proporções de genes sobre-expressos e reprimidos, por grupos de genes, de culturas de células MC3T3-E1 (sub-clone 14) crescidas sobre Bioglass ${ }^{\circledR} 45 \mathrm{~S} 5$ (45S5), Biosilicato ${ }^{\circledR}$ (Bio) e Biosilicato $^{\circledR}$ para scaffold (Bio-sc) por períodos de 7,12 e 21 dias, em comparação àquelas sobre borosilicato. Marcações com tons escuros representam sobre-expressão (verde) ou repressão (vermelho) de uma proporção maior ou igual a $50 \%$ dos genes avaliados em cada grupo, enquanto que aquelas em tons claros, inferior a $50 \%$

\begin{tabular}{|c|c|c|c|c|c|c|c|c|c|}
\hline \multirow[t]{2}{*}{$\begin{array}{l}\text { Período/Grupos } \\
\text { de genes }\end{array}$} & \multicolumn{3}{|c|}{7 dias } & \multicolumn{3}{|c|}{12 dias } & \multicolumn{3}{|c|}{21 dias } \\
\hline & $45 S 5$ & Bio & Bio-sc & $45 S 5$ & Bio & Bio-sc & $45 S 5$ & Bio & Bio-sc \\
\hline \multicolumn{10}{|l|}{$\begin{array}{l}\text { Sobre- } \\
\text { expressos }\end{array}$} \\
\hline $\begin{array}{l}\text { Proteínas da } \\
\text { matriz óssea }\end{array}$ & $4 / 5$ & $3 / 5$ & $3 / 5$ & $1 / 5$ & $3 / 5$ & $2 / 5$ & $2 / 5$ & $2 / 5$ & $2 / 5$ \\
\hline $\begin{array}{l}\text { Superfamília } \\
\text { das BMPs }\end{array}$ & $5 / 10$ & $5 / 10$ & $0 / 10$ & $1 / 10$ & $3 / 10$ & $2 / 10$ & $6 / 10$ & $2 / 10$ & $3 / 10$ \\
\hline Receptores & $10 / 16$ & $5 / 16$ & $4 / 16$ & $0 / 16$ & $9 / 16$ & $4 / 16$ & $12 / 16$ & $6 / 16$ & $10 / 16$ \\
\hline $\begin{array}{l}\text { Fatores de } \\
\text { crescimento }\end{array}$ & $4 / 10$ & $1 / 10$ & $0 / 10$ & $1 / 10$ & $6 / 10$ & $4 / 10$ & $6 / 10$ & $2 / 10$ & $3 / 10$ \\
\hline $\begin{array}{l}\text { Receptores de } \\
\text { integrina }\end{array}$ & $5 / 6$ & $3 / 6$ & $0 / 6$ & $0 / 6$ & $3 / 6$ & $4 / 6$ & $5 / 6$ & $3 / 6$ & $5 / 6$ \\
\hline Colágeno & $6 / 14$ & $7 / 14$ & $3 / 14$ & $2 / 14$ & $8 / 14$ & $5 / 14$ & $10 / 14$ & $6 / 14$ & $10 / 14$ \\
\hline $\begin{array}{l}\text { Relacionados à } \\
\text { cartilagem }\end{array}$ & $1 / 2$ & $0 / 2$ & $0 / 2$ & $0 / 2$ & $0 / 2$ & $0 / 2$ & $1 / 2$ & $1 / 2$ & $1 / 2$ \\
\hline Metaloproteinases & $1 / 4$ & $0 / 4$ & $0 / 4$ & $0 / 4$ & $3 / 4$ & $2 / 4$ & $2 / 4$ & $1 / 4$ & $2 / 4$ \\
\hline $\begin{array}{l}\text { Fatores de } \\
\text { transcrição }\end{array}$ & $2 / 8$ & $1 / 8$ & $0 / 8$ & $0 / 8$ & $3 / 8$ & $4 / 8$ & $7 / 8$ & $5 / 8$ & $8 / 8$ \\
\hline Outros genes & $2 / 9$ & $2 / 9$ & $0 / 9$ & $0 / 9$ & $2 / 9$ & $3 / 9$ & $4 / 9$ & $2 / 9$ & $3 / 9$ \\
\hline \multicolumn{10}{|l|}{ Reprimidos } \\
\hline $\begin{array}{l}\text { Proteínas da } \\
\text { matriz óssea }\end{array}$ & $0 / 5$ & $0 / 5$ & $1 / 5$ & $2 / 5$ & $0 / 5$ & $0 / 5$ & $0 / 5$ & $0 / 5$ & $0 / 5$ \\
\hline $\begin{array}{l}\text { Superfamília } \\
\text { das BMPs }\end{array}$ & $0 / 10$ & $1 / 10$ & $1 / 10$ & $2 / 10$ & $0 / 10$ & $0 / 10$ & $0 / 10$ & $0 / 10$ & $0 / 10$ \\
\hline Receptores & $1 / 16$ & $3 / 16$ & $2 / 16$ & $4 / 16$ & $1 / 16$ & $0 / 16$ & $0 / 16$ & $0 / 16$ & $0 / 16$ \\
\hline $\begin{array}{l}\text { Fatores de } \\
\text { crescimento }\end{array}$ & $0 / 10$ & $2 / 10$ & $1 / 10$ & $2 / 10$ & $1 / 10$ & $1 / 10$ & $0 / 10$ & $0 / 10$ & $0 / 10$ \\
\hline $\begin{array}{l}\text { Receptores de } \\
\text { integrina }\end{array}$ & $0 / 6$ & $0 / 6$ & $0 / 6$ & $1 / 6$ & $0 / 6$ & $1 / 6$ & $0 / 6$ & $0 / 6$ & $0 / 6$ \\
\hline Colágeno & $1 / 14$ & $5 / 14$ & $3 / 14$ & $7 / 14$ & $0 / 14$ & $4 / 14$ & $0 / 14$ & $1 / 14$ & $0 / 14$ \\
\hline $\begin{array}{l}\text { Relacionados à } \\
\text { cartilagem }\end{array}$ & $0 / 2$ & $1 / 2$ & $0 / 2$ & $2 / 2$ & $0 / 2$ & $0 / 2$ & $0 / 2$ & $0 / 2$ & $0 / 2$ \\
\hline Metaloproteinases & $1 / 4$ & $1 / 4$ & $1 / 4$ & $0 / 4$ & $0 / 4$ & $0 / 4$ & $0 / 4$ & $0 / 4$ & $0 / 4$ \\
\hline $\begin{array}{l}\text { Fatores de } \\
\text { transcrição }\end{array}$ & $0 / 8$ & $4 / 8$ & $0 / 8$ & $3 / 8$ & $0 / 8$ & $0 / 8$ & $0 / 8$ & $0 / 8$ & $0 / 8$ \\
\hline Outros genes & $0 / 9$ & $1 / 9$ & $1 / 9$ & $1 / 9$ & $0 / 9$ & $0 / 9$ & $0 / 9$ & $1 / 9$ & $0 / 9$ \\
\hline
\end{tabular}


Tabela 6. Expressão gênica por PCR Array de células MC3T3-E1 (sub-clone 14) cultivadas por 7 dias sobre Bioglass ${ }^{\circledR} 45 S 5$ (45S5), Biosilicato ${ }^{\circledR}$ (Bio) e Biosilicato ${ }^{\circledR}$ para scaffold (Bio-sc). Os valores de expressão relativa foram normalizados pelo gene constitutivo beta-actina (ACTB) e calibrados em relação ao controle bioativo Bioglass ${ }^{\circledR} 45 \mathrm{~S} 5$ (45S5). Com cut-off de 1,5 e p<0,05 utilizando a correção de Benjamin-Hochberg, valores positivos indicam aumento e valores negativos, diminuição da expressão de cada gene avaliado. O traço indica que não houve alteração na expressão gênica

\begin{tabular}{|c|c|c|c|}
\hline \multirow{2}{*}{ Símbolo } & \multirow{2}{*}{ Descrição } & \multicolumn{2}{|c|}{ Expressão Relativa (fold) - 7 dias } \\
\hline & & Bio & Bio-sc \\
\hline \multicolumn{4}{|c|}{ Proteínas não colágenas da matriz óssea } \\
\hline Alpl & Alkaline phosphatase, liver/bone/kidney & $-3,54$ & $-2,01$ \\
\hline Bgn & Biglycan & $-2,45$ & $-1,64$ \\
\hline Dmp1 & Dentin matrix acidic phosphoprotein 1 & $-8,63$ & $-4,01$ \\
\hline Fn1 & Fibronectin 1 & $-2,08$ & - \\
\hline Ahsg & Alpha-2-HS-glycoprotein & - & $-2,55$ \\
\hline \multicolumn{4}{|c|}{ Superfamília das proteínas morfogenéticas ósseas } \\
\hline Bmp1 & Bone morphogenetic protein 1 & $-4,55$ & - \\
\hline Bmp2 & Bone morphogenetic protein 2 & - & - \\
\hline Вmp3 & Bone morphogenetic protein 3 & - & - \\
\hline Bmp4 & Bone morphogenetic protein 4 & $-5,01$ & $-1,64$ \\
\hline Bmp5 & Bone morphogenetic protein 5 & $-2,64$ & $-2,42$ \\
\hline Bmp6 & Bone morphogenetic protein 6 & - & - \\
\hline Gdf10 & Growth differentiation factor 10 & $-3,00$ & $-2,06$ \\
\hline Tgfb1 & Transforming growth factor, beta 1 & - & - \\
\hline Tgfb2 & Transforming growth factor, beta 2 & $-4,38$ & $-1,72$ \\
\hline Tgfb3 & Transforming growth factor, beta 3 & $-2,53$ & - \\
\hline \multicolumn{4}{|l|}{ Receptores } \\
\hline Cd36 & CD36 molecule & - & - \\
\hline Cdh11 & Cadherin 11 & $-20,73$ & - \\
\hline Fgfr1 & Fibroblast growth factor receptor 1 & $-5,52$ & $-1,55$ \\
\hline Fgfr2 & Fibroblast growth factor receptor 2 & $-9,50$ & $-1,56$ \\
\hline Flt1 & Fms-like tyrosine kinase 1 & $-3,91$ & - \\
\hline Icam1 & Intercellular adhesion molecule 1 & - & - \\
\hline Scarb1 & Scavenger receptor class $B$, member 1 & $-1,79$ & - \\
\hline Tgfbr1 & Transforming growth factor, beta receptor I & $-4,03$ & $-1,66$ \\
\hline Tgfbr2 & Transforming growth factor, beta receptor II & - & - \\
\hline Tgfbr3 & Transforming growth factor, beta receptor III & $-4,84$ & $-2,72$ \\
\hline Vcam1 & Vascular cell adhesion molecule 1 & $-7,83$ & $-1,80$ \\
\hline$V d r$ & Vitamin D receptor & $-10,70$ & - \\
\hline Igf1r & Insulin-like growth factor 1 receptor & - & $-2,04$ \\
\hline Phex & Phosphate regulating endopeptidase homolog, $X$-linked & $-12,53$ & $-1,94$ \\
\hline Bmpr1a & Bone morphogenetic protein receptor, type $1 \mathrm{~A}$ & $-16,94$ & $-2,19$ \\
\hline Bmpr1b & Bone morphogenetic protein receptor, type $1 B$ & $-4,26$ & $-2,06$ \\
\hline \multicolumn{4}{|c|}{ Fatores de crescimento } \\
\hline Egf & Epidermal growth factor & $-7,20$ & $-2,49$ \\
\hline Fgf1 & Fibroblast growth factor 1 & - & - \\
\hline Fqf2 & Fibroblast growth factor 2 & - & - \\
\hline Fqf3 & Fibroblast growth factor 3 & $-6,58$ & $-2,07$ \\
\hline Igf1 & Insulin-like growth factor 1 & $-10,46$ & - \\
\hline Pdgfa & Platelet derived growth factor, alpha & $-3,74$ & \\
\hline Vegfa & Vascular endothelial growth factor $A$ & $-3,26$ & - \\
\hline Vegfb & Vascular endothelial growth factor $B$ & $-1,84$ & $-1,54$ \\
\hline Csf2 & Colony stimulating factor 2 (granulocyte-macrophage) & $-2,90$ & $-1,50$ \\
\hline Csf3 & Colony stimulating factor 3 (granulocyte) & - & - \\
\hline Receptores c & grina & & \\
\hline
\end{tabular}




\begin{tabular}{|c|c|c|c|}
\hline \multirow{2}{*}{ Símbolo } & \multirow{2}{*}{ Descrição } & \multicolumn{2}{|c|}{ Expressão Relativa (fold) - 7 dias } \\
\hline & & Bio & Bio-sc \\
\hline $\operatorname{ltga2}$ & Integrin alpha 2 & - & - \\
\hline $\operatorname{ltga} 2 b$ & Integrin alpha $2 b$ & $-3,63$ & - \\
\hline $\operatorname{ltga3}$ & Integrin alpha 3 & $-1,66$ & - \\
\hline Itgam & Integrin alpha $M$ & $-2,61$ & - \\
\hline Itgav & Integrin alpha $\mathrm{V}$ & $-10,45$ & $-2,58$ \\
\hline $\operatorname{ltg} 1$ & Integrin beta 1 (fibronectin receptor beta) & $-3,43$ & $-1,56$ \\
\hline \multicolumn{4}{|c|}{ 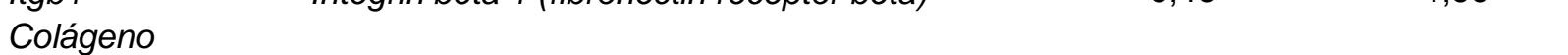 } \\
\hline Col10a1 & Collagen, type $X$, alpha 1 & $-4,99$ & $-2,18$ \\
\hline Col11a1 & Collagen, type XI, alpha 1 & $-18,47$ & - \\
\hline Col12a1 & Collagen, type XII, alpha 1 & $-6,78$ & - \\
\hline Col14a1 & Collagen, type XIV, alpha 1 & $-1,95$ & $-1,58$ \\
\hline Col1a1 & Collagen, type I, alpha 1 & - & - \\
\hline Col1a2 & Collagen, type I, alpha 2 & $-7,39$ & - \\
\hline Col2a1 & Collagen, type II, alpha 1 & $-4,38$ & - \\
\hline Col3a1 & Collagen, type III, alpha 1 & $-5,07$ & $-1,50$ \\
\hline Col4a1 & Collagen, type IV, alpha 1 & $-2,64$ & - \\
\hline Col4a2 & Collagen, type IV, alpha 2 & $-3,10$ & - \\
\hline Col5a1 & Collagen, type $V$, alpha 1 & $-1,90$ & - \\
\hline Col6a1 & Collagen, type VI, alpha 1 & $-3,42$ & - \\
\hline Col6a2 & Collagen, type VI, alpha 2 & - & 1,56 \\
\hline Col7a1 & Collagen, type VII, alpha 1 & $-2,98$ & $-1,62$ \\
\hline \multicolumn{4}{|c|}{ Genes relacionados à cartilagem } \\
\hline Comp & Cartilage oligomeric matrix protein & $-6,79$ & $-2,43$ \\
\hline Sox9 & SRY - box containing gene 9 & $-3,20$ & - \\
\hline \multicolumn{4}{|c|}{ Metaloproteinases } \\
\hline Mmp10 & Matrix metallopeptidase 10 & - & - \\
\hline Mmp2 & Matrix metallopeptidase 2 & $-4,03$ & - \\
\hline Mmp8 & Matrix metallopeptidase 8 & $-5,80$ & $-2,11$ \\
\hline Mmp9 & Matrix metallopeptidase 9 & $-1,80$ & - \\
\hline \multicolumn{4}{|c|}{ Fatores de Transcrição } \\
\hline Ms $x 1$ & Homeobox,msh-like 1 & $-17,40$ & - \\
\hline Nfkb1 & Nuclear factor of kappa in B-cells 1, p105 & $-4,29$ & $-1,89$ \\
\hline Runx2 & Runt related transcription factor 2 & $-3,11$ & - \\
\hline Smad1 & MAD homolog 1 (Drosophila) & $-11,96$ & - \\
\hline Smad2 & MAD homolog 2 (Drosophila) & $-9,26$ & $-1,53$ \\
\hline Smad3 & MAD homolog 3 (Drosophila) & $-1,84$ & - \\
\hline Smad4 & MAD homolog 4 (Drosophila) & $-2,66$ & - \\
\hline Twist1 & Twist homolog 1 (Drosophila) & $-6,80$ & - \\
\hline \multicolumn{4}{|l|}{ Outros genes } \\
\hline Ctsk & Cathepsin K & $-4,60$ & - \\
\hline Serpinh1 & Serine (or cysteine) peptidase inhibitor, clade $\mathrm{H}$, member 1 & - & - \\
\hline Tuft1 & Tuftelin 1 & - & - \\
\hline Tfip11 & Tuftelin interacting protein 11 & $-4,58$ & - \\
\hline Anxa5 & Annexin A5 & $-1,80$ & - \\
\hline$A m b n$ & Ameloblastin & $-3,29$ & - \\
\hline Enam & Enamelin & - & - \\
\hline Sost & Sclerostin & $-4,57$ & $-3,07$ \\
\hline Tnf & Tumor necrosis factor & - & - \\
\hline
\end{tabular}


Tabela 7. Expressão gênica por PCR Array de células MC3T3-E1 (sub-clone 14) cultivadas por 12 dias sobre Bioglass ${ }^{\circledR} 45 \mathrm{~S} 5$ (45S5), Biosilicato ${ }^{\circledR}$ (Bio) e Biosilicato ${ }^{\circledR}$ para scaffold (Bio-sc). Os valores de expressão relativa foram normalizados pelo gene constitutivo beta-actina (ACTB) e calibrados em relação ao controle bioativo Bioglass ${ }^{\circledR} 45 \mathrm{~S} 5$ (45S5). Com cut-off de 1,5 e p<0,05 utilizando a correção de Benjamin-Hochberg, valores positivos indicam aumento e valores negativos, diminuição da expressão de cada gene avaliado. $O$ traço indica que não houve alteração na expressão gênica

\begin{tabular}{|c|c|c|c|}
\hline \multirow{2}{*}{ Símbolo } & \multirow{2}{*}{ Descrição } & \multicolumn{2}{|c|}{ Expressão Relativa (fold) - 12 dias } \\
\hline & & Bio & Bio-sc \\
\hline \multicolumn{4}{|c|}{ Proteínas não colágenas da matriz óssea } \\
\hline Alpl & Alkaline phosphatase, liver/bone/kidney & - & - \\
\hline Bgn & Biglycan & 2,34 & - \\
\hline Dmp1 & Dentin matrix acidic phosphoprotein 1 & - & 2,04 \\
\hline Fn1 & Fibronectin 1 & 5,63 & - \\
\hline Ahsg & Alpha-2-HS-glycoprotein & - & - \\
\hline \multicolumn{4}{|c|}{ Superfamília das proteínas morfogenéticas ósseas } \\
\hline Bmp1 & Bone morphogenetic protein 1 & 2,04 & 2,94 \\
\hline Bmp2 & Bone morphogenetic protein 2 & $-3,25$ & - \\
\hline Bmp3 & Bone morphogenetic protein 3 & - & - \\
\hline Bmp4 & Bone morphogenetic protein 4 & 1,62 & 1,85 \\
\hline Bmp5 & Bone morphogenetic protein 5 & - & - \\
\hline Bmp6 & Bone morphogenetic protein 6 & $-2,91$ & - \\
\hline Gdf10 & Growth differentiation factor 10 & - & - \\
\hline Tgfb1 & Transforming growth factor, beta 1 & - & - \\
\hline Tgfb2 & Transforming growth factor, beta 2 & 3,42 & 2,26 \\
\hline Tgfb3 & Transforming growth factor, beta 3 & - & - \\
\hline \multicolumn{4}{|l|}{ Receptores } \\
\hline Cd36 & CD36 molecule & $-4,09$ & - \\
\hline Cdh11 & Cadherin 11 & 1,86 & 2,88 \\
\hline Fgfr1 & Fibroblast growth factor receptor 1 & 2,32 & 2,26 \\
\hline Fgfr2 & Fibroblast growth factor receptor 2 & 2,16 & 1,96 \\
\hline Flt1 & Fms-like tyrosine kinase 1 & 2,46 & - \\
\hline Icam1 & Intercellular adhesion molecule 1 & 2,12 & - \\
\hline Scarb1 & Scavenger receptor class $B$, member 1 & - & - \\
\hline Tgfbr1 & Transforming growth factor, beta receptor I & 2,29 & - \\
\hline Tgfbr2 & Transforming growth factor, beta receptor II & 1,56 & - \\
\hline Tgfbr3 & Transforming growth factor, beta receptor III & 2,23 & - \\
\hline Vcam1 & Vascular cell adhesion molecule 1 & 2,05 & 2,22 \\
\hline$V d r$ & Vitamin D receptor & 1,97 & 2,37 \\
\hline Igf1r & Insulin-like growth factor 1 receptor & 3,62 & - \\
\hline Phex & Phosphate regulating endopeptidase homolog, $X$-linked & 4,15 & 4,09 \\
\hline Bmpr1a & Bone morphogenetic protein receptor, type $1 \mathrm{~A}$ & 3,51 & 2,48 \\
\hline Bmpr1b & Bone morphogenetic protein receptor, type $1 B$ & 1,61 & - \\
\hline \multicolumn{4}{|c|}{ Fatores de crescimento } \\
\hline Egf & Epidermal growth factor & 2,42 & - \\
\hline Fgf1 & Fibroblast growth factor 1 & 1,98 & 2,22 \\
\hline Fgf2 & Fibroblast growth factor 2 & 2,09 & - \\
\hline Fgf3 & Fibroblast growth factor 3 & 1,66 & 1,90 \\
\hline Igf1 & Insulin-like growth factor 1 & 2,34 & 2,73 \\
\hline Pdgfa & Platelet derived growth factor, alpha & 1,62 & 1,81 \\
\hline Vegfa & Vascular endothelial growth factor $A$ & 2,70 & 1,55 \\
\hline Vegfb & Vascular endothelial growth factor $B$ & 1,56 & - \\
\hline Csf2 & Colony stimulating factor 2 (granulocyte-macrophage) & - & - \\
\hline Csf3 & Colony stimulating factor 3 (granulocyte) & $-2,25$ & - \\
\hline Receptores $d t$ & grina & & \\
\hline
\end{tabular}




\begin{tabular}{|c|c|c|c|}
\hline \multirow{2}{*}{ Símbolo } & \multirow{2}{*}{ Descrição } & \multicolumn{2}{|c|}{ Expressão Relativa (fold) - 12 dias } \\
\hline & & Bio & Bio-sc \\
\hline Itga2 & Integrin alpha 2 & 1,66 & - \\
\hline $\operatorname{ltg} 2 b$ & Integrin alpha $2 b$ & - & 3,72 \\
\hline Itga3 & Integrin alpha 3 & 2,07 & - \\
\hline Itgam & Integrin alpha $M$ & - & 1,78 \\
\hline Itgav & Integrin alpha $V$ & 4,61 & 1,81 \\
\hline $\operatorname{ltg} 1$ & Integrin beta 1 (fibronectin receptor beta) & 1,64 & 2,30 \\
\hline \multicolumn{4}{|c|}{ 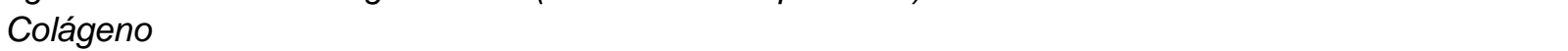 } \\
\hline Col10a1 & Collagen, type $X$, alpha 1 & - & 7,64 \\
\hline Col11a1 & Collagen, type XI, alpha 1 & 5,64 & 3,14 \\
\hline Col12a1 & Collagen, type XII, alpha 1 & 6,84 & - \\
\hline Col14a1 & Collagen, type XIV, alpha 1 & - & - \\
\hline Colla1 & Collagen, type I, alpha 1 & 3,29 & - \\
\hline Col1a2 & Collagen, type I, alpha 2 & 3,51 & 2,21 \\
\hline Col2a1 & Collagen, type II, alpha 1 & 2,35 & 2,46 \\
\hline Col3a1 & Collagen, type III, alpha 1 & 3,94 & 1,93 \\
\hline Col4a1 & Collagen, type IV, alpha 1 & 2,92 & - \\
\hline Col4a2 & Collagen, type IV, alpha 2 & - & - \\
\hline Col5a1 & Collagen, type $V$, alpha 1 & 3,52 & - \\
\hline Col6a1 & Collagen, type VI, alpha 1 & 1,89 & 1,92 \\
\hline Col6a2 & Collagen, type VI, alpha 2 & 1,93 & 1,64 \\
\hline Col7a1 & Collagen, type VII, alpha 1 & - & - \\
\hline \multicolumn{4}{|c|}{ Genes relacionados à cartilagem } \\
\hline Comp & Cartilage oligomeric matrix protein & 2,02 & 2,13 \\
\hline Sox9 & SRY - box containing gene 9 & 2,66 & - \\
\hline \multicolumn{4}{|c|}{ Metaloproteinases } \\
\hline Mmp10 & Matrix metallopeptidase 10 & - & - \\
\hline Mmp2 & Matrix metallopeptidase 2 & 2,81 & 2,22 \\
\hline Mmp8 & Matrix metallopeptidase 8 & 2,23 & 1,59 \\
\hline Mmp9 & Matrix metallopeptidase 9 & 2,77 & 2,89 \\
\hline \multicolumn{4}{|c|}{ Fatores de Transcrição } \\
\hline Ms $x 1$ & Homeobox,msh-like 1 & 1,89 & 3,74 \\
\hline$N f k b 1$ & Nuclear factor of kappa in B-cells 1, p105 & 2,01 & 1,87 \\
\hline Runx2 & Runt related transcription factor 2 & 3,49 & - \\
\hline Smad1 & MAD homolog 1 (Drosophila) & - & 1,84 \\
\hline Smad2 & MAD homolog 2 (Drosophila) & 2,09 & 1,97 \\
\hline Smad3 & MAD homolog 3 (Drosophila) & 2,19 & - \\
\hline Smad4 & MAD homolog 4 (Drosophila) & - & 2,05 \\
\hline Twist1 & Twist homolog 1 (Drosophila) & 1,52 & 2,76 \\
\hline \multicolumn{4}{|l|}{ Outros genes } \\
\hline Ctsk & Cathepsin $K$ & 1,86 & 3,59 \\
\hline Serpinh1 & Serine (or cysteine) peptidase inhibitor, clade $\mathrm{H}$, member 1 & - & - \\
\hline Tuft1 & Tuftelin 1 & $-1,72$ & - \\
\hline Tfip11 & Tuftelin interacting protein 11 & - & 2,22 \\
\hline Anxa5 & Annexin A5 & - & 1,79 \\
\hline$A m b n$ & Ameloblastin & 3,47 & - \\
\hline Enam & Enamelin & - & - \\
\hline Sost & Sclerostin & 1,76 & - \\
\hline Tnf & Tumor necrosis factor & $-2,69$ & - \\
\hline
\end{tabular}


Tabela 8. Expressão gênica por PCR Array de células MC3T3-E1 (sub-clone 14) cultivadas por 21 dias sobre Bioglass ${ }^{\circledR} 45 \mathrm{~S} 5$ (45S5), Biosilicato ${ }^{\circledR}$ (Bio) e Biosilicato ${ }^{\circledR}$ para scaffold (Bio-sc). Os valores de expressão relativa foram normalizados pelo gene constitutivo beta-actina (ACTB) e calibrados em relação ao controle bioativo Bioglass ${ }^{\circledR} 45 S 5$ (45S5). Com cut-off de 1,5 e $p<0,05$ utilizando a correção de Benjamin-Hochberg, valores positivos indicam aumento e valores negativos, diminuição da expressão de cada gene avaliado. $O$ traço indica que não houve alteração na expressão gênica

\begin{tabular}{|c|c|c|c|}
\hline \multirow{2}{*}{ Símbolo } & \multirow{2}{*}{ Descrição } & \multicolumn{2}{|c|}{ Expressão Relativa (fold) - 21 dias } \\
\hline & & Bio & Bio-sc \\
\hline \multicolumn{4}{|c|}{ Proteínas não colágenas da matriz óssea } \\
\hline Alpl & Alkaline phosphatase, liver/bone/kidney & - & - \\
\hline Bgn & Biglycan & - & - \\
\hline Dmp1 & Dentin matrix acidic phosphoprotein 1 & - & $-3,35$ \\
\hline Fn1 & Fibronectin 1 & - & - \\
\hline Ahsg & Alpha-2-HS-glycoprotein & - & - \\
\hline \multicolumn{4}{|c|}{ Superfamília das proteínas morfogenéticas ósseas } \\
\hline Bmp1 & Bone morphogenetic protein 1 & - & 1,88 \\
\hline Bmp2 & Bone morphogenetic protein 2 & - & - \\
\hline Bmp3 & Bone morphogenetic protein 3 & - & - \\
\hline Bmp4 & Bone morphogenetic protein 4 & - & - \\
\hline Bmp5 & Bone morphogenetic protein 5 & - & - \\
\hline Bmp6 & Bone morphogenetic protein 6 & - & - \\
\hline Gdf10 & Growth differentiation factor 10 & - & - \\
\hline Tgfb1 & Transforming growth factor, beta 1 & - & - \\
\hline Tgfb2 & Transforming growth factor, beta 2 & - & - \\
\hline Tgfb3 & Transforming growth factor, beta 3 & $-1,62$ & - \\
\hline \multicolumn{4}{|l|}{ Receptores } \\
\hline Cd36 & CD36 molecule & - & - \\
\hline Cdh11 & Cadherin 11 & - & 2,06 \\
\hline Fgfr1 & Fibroblast growth factor receptor 1 & - & - \\
\hline Fgfr2 & Fibroblast growth factor receptor 2 & - & 1,67 \\
\hline Flt1 & Fms-like tyrosine kinase 1 & - & - \\
\hline Icam1 & Intercellular adhesion molecule 1 & - & - \\
\hline Scarb1 & Scavenger receptor class $B$, member 1 & - & - \\
\hline Tgfbr1 & Transforming growth factor, beta receptor I & - & - \\
\hline Tgfbr2 & Transforming growth factor, beta receptor II & - & - \\
\hline Tgfbr3 & Transforming growth factor, beta receptor III & - & - \\
\hline Vcam1 & Vascular cell adhesion molecule 1 & - & - \\
\hline$V d r$ & Vitamin D receptor & - & 2,97 \\
\hline Igf1r & Insulin-like growth factor 1 receptor & - & - \\
\hline Phex & Phosphate regulating endopeptidase homolog, $X$-linked & $-1,84$ & - \\
\hline Bmpr1a & Bone morphogenetic protein receptor, type $1 \mathrm{~A}$ & - & 1,50 \\
\hline Bmpr1b & Bone morphogenetic protein receptor, type $1 B$ & $-1,67$ & $-1,56$ \\
\hline \multicolumn{4}{|c|}{ Fatores de crescimento } \\
\hline Egf & Epidermal growth factor & - & $-1,52$ \\
\hline Fgf1 & Fibroblast growth factor 1 & - & - \\
\hline Fgf2 & Fibroblast growth factor 2 & - & - \\
\hline Fqf3 & Fibroblast growth factor 3 & - & - \\
\hline Igf1 & Insulin-like growth factor 1 & - & 1,92 \\
\hline Pdgfa & Platelet derived growth factor, alpha & - & - \\
\hline Vegfa & Vascular endothelial growth factor $A$ & - & - \\
\hline Vegfb & Vascular endothelial growth factor $B$ & - & - \\
\hline Csf2 & Colony stimulating factor 2 (granulocyte-macrophage) & - & - \\
\hline Csf3 & Colony stimulating factor 3 (granulocyte) & - & - \\
\hline Receptores $d t$ & grina & & \\
\hline
\end{tabular}




\begin{tabular}{|c|c|c|c|}
\hline \multirow{2}{*}{ Símbolo } & \multirow{2}{*}{ Descrição } & \multicolumn{2}{|c|}{ Expressão Relativa (fold) - 21 dias } \\
\hline & & Bio & Bio-sc \\
\hline Itga2 & Integrin alpha 2 & - & - \\
\hline $\operatorname{ltga} 2 b$ & Integrin alpha $2 b$ & $-1,69$ & 1,70 \\
\hline $\operatorname{ltga3}$ & Integrin alpha 3 & - & - \\
\hline Itgam & Integrin alpha $M$ & - & - \\
\hline Itgav & Integrin alpha $V$ & - & - \\
\hline $\operatorname{ltg} 1$ & Integrin beta 1 (fibronectin receptor beta) & - & - \\
\hline \multicolumn{4}{|c|}{ 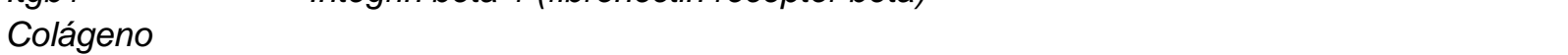 } \\
\hline Col10a1 & Collagen, type $X$, alpha 1 & - & $-8,61$ \\
\hline Col11a1 & Collagen, type XI, alpha 1 & - & 2,16 \\
\hline Col12a1 & Collagen, type XII, alpha 1 & - & - \\
\hline Col14a1 & Collagen, type XIV, alpha 1 & - & $-1,68$ \\
\hline Col1a1 & Collagen, type I, alpha 1 & - & - \\
\hline Col1a2 & Collagen, type I, alpha 2 & - & 1,88 \\
\hline Col2a1 & Collagen, type II, alpha 1 & - & - \\
\hline Col3a1 & Collagen, type III, alpha 1 & - & - \\
\hline Col4a1 & Collagen, type IV, alpha 1 & - & - \\
\hline Col4a2 & Collagen, type IV, alpha 2 & - & - \\
\hline Col5a1 & Collagen, type $V$, alpha 1 & - & - \\
\hline Col6a1 & Collagen, type VI, alpha 1 & - & - \\
\hline Col6a2 & Collagen, type VI, alpha 2 & - & - \\
\hline Col7a1 & Collagen, type VII, alpha 1 & - & - \\
\hline \multicolumn{4}{|c|}{ Genes relacionados à cartilagem } \\
\hline Comp & Cartilage oligomeric matrix protein & - & - \\
\hline Sox9 & SRY - box containing gene 9 & - & - \\
\hline \multicolumn{4}{|c|}{ Metaloproteinases } \\
\hline Mmp10 & Matrix metallopeptidase 10 & - & - \\
\hline Mmp2 & Matrix metallopeptidase 2 & - & 1,53 \\
\hline Mmp8 & Matrix metallopeptidase 8 & - & - \\
\hline Mmp9 & Matrix metallopeptidase 9 & - & 2,23 \\
\hline \multicolumn{4}{|c|}{ Fatores de Transcrição } \\
\hline Ms $x 1$ & Homeobox,msh-like 1 & - & 2,42 \\
\hline$N f k b 1$ & Nuclear factor of kappa in B-cells 1, p105 & - & - \\
\hline Runx2 & Runt related transcription factor 2 & - & - \\
\hline Smad1 & MAD homolog 1 (Drosophila) & - & 2,53 \\
\hline Smad2 & MAD homolog 2 (Drosophila) & - & - \\
\hline Smad3 & MAD homolog 3 (Drosophila) & - & - \\
\hline Smad4 & MAD homolog 4 (Drosophila) & - & - \\
\hline Twist1 & Twist homolog 1 (Drosophila) & - & - \\
\hline \multicolumn{4}{|l|}{ Outros genes } \\
\hline Ctsk & Cathepsin $\mathrm{K}$ & - & - \\
\hline Serpinh1 & Serine (or cysteine) peptidase inhibitor, clade $H$, member 1 & - & - \\
\hline Tuft1 & Tuftelin 1 & - & - \\
\hline Tfip11 & Tuftelin interacting protein 11 & - & - \\
\hline Anxa5 & Annexin A5 & - & - \\
\hline Ambn & Ameloblastin & $-1,78$ & - \\
\hline Enam & Enamelin & - & - \\
\hline Sost & Sclerostin & - & - \\
\hline Tnf & Tumor necrosis factor & - & - \\
\hline
\end{tabular}


Tabela 9. Proporções de genes sobre-expressos e reprimidos, por grupos de genes, de culturas de células MC3T3-E1 (sub-clone 14) crescidas sobre Biosilicato ${ }^{\circledR}$ (Bio) e Biosilicato ${ }^{\circledR}$ para scaffold (Biosc) por períodos de 7, 12 e 21 dias, em comparação àquelas sobre Bioglass ${ }^{\circledR} 45 \mathrm{~S} 5$ (45S5). Marcações com tons escuros representam sobre-expressão (verde) ou repressão (vermelho) de uma proporção maior ou igual a $50 \%$ dos genes avaliados em cada grupo, enquanto que aquelas em tons claros, inferior a $50 \%$

\begin{tabular}{|c|c|c|c|c|c|c|}
\hline \multirow[t]{2}{*}{$\begin{array}{l}\text { Período/Grupos } \\
\text { de genes }\end{array}$} & \multicolumn{2}{|c|}{7 dias } & \multicolumn{2}{|c|}{12 dias } & \multicolumn{2}{|c|}{21 dias } \\
\hline & Bio & Bio-sc & Bio & Bio-sc & Bio & Bio-sc \\
\hline \multicolumn{7}{|l|}{ Sobre-expressos } \\
\hline $\begin{array}{l}\text { Proteínas da } \\
\text { matriz óssea }\end{array}$ & $0 / 5$ & $0 / 5$ & $2 / 5$ & $1 / 5$ & $0 / 5$ & $0 / 5$ \\
\hline $\begin{array}{l}\text { Superfamília das } \\
\text { BMPs }\end{array}$ & $0 / 10$ & $0 / 10$ & $3 / 10$ & $3 / 10$ & $0 / 10$ & $1 / 10$ \\
\hline Receptores & $0 / 16$ & $0 / 16$ & $14 / 16$ & $7 / 16$ & $0 / 16$ & $4 / 16$ \\
\hline $\begin{array}{l}\text { Fatores de } \\
\text { crescimento }\end{array}$ & $0 / 10$ & 0/10 & $8 / 10$ & $5 / 10$ & $0 / 10$ & $1 / 10$ \\
\hline $\begin{array}{l}\text { Receptores de } \\
\text { integrina }\end{array}$ & $0 / 6$ & $0 / 6$ & $4 / 6$ & $4 / 6$ & $0 / 6$ & $1 / 6$ \\
\hline Colágeno & $0 / 16$ & $1 / 16$ & $10 / 16$ & $7 / 16$ & $0 / 16$ & $2 / 16$ \\
\hline $\begin{array}{l}\text { Relacionados à } \\
\text { cartilagem }\end{array}$ & $0 / 2$ & $0 / 2$ & $2 / 2$ & $1 / 2$ & $0 / 2$ & $0 / 2$ \\
\hline Metaloproteinases & $0 / 4$ & $0 / 4$ & $3 / 4$ & $3 / 4$ & $0 / 4$ & $2 / 4$ \\
\hline $\begin{array}{l}\text { Fatores de } \\
\text { transcrição }\end{array}$ & $0 / 8$ & $0 / 8$ & $6 / 8$ & $6 / 8$ & $0 / 8$ & $2 / 8$ \\
\hline Outros genes & $0 / 9$ & $0 / 9$ & $3 / 9$ & $3 / 9$ & $0 / 9$ & $0 / 9$ \\
\hline \multicolumn{7}{|l|}{ Reprimidos } \\
\hline $\begin{array}{l}\text { Proteínas da } \\
\text { matriz óssea }\end{array}$ & $4 / 5$ & $4 / 5$ & $0 / 5$ & $0 / 5$ & $0 / 5$ & $1 / 5$ \\
\hline $\begin{array}{l}\text { Superfamília das } \\
\text { BMPs }\end{array}$ & $6 / 10$ & $4 / 10$ & $2 / 10$ & 0/10 & $1 / 10$ & $0 / 10$ \\
\hline Receptores & $12 / 16$ & 9/16 & $1 / 16$ & $0 / 16$ & $2 / 16$ & $1 / 16$ \\
\hline $\begin{array}{l}\text { Fatores de } \\
\text { crescimento }\end{array}$ & $7 / 10$ & $4 / 10$ & $1 / 10$ & $0 / 10$ & $0 / 10$ & $1 / 10$ \\
\hline $\begin{array}{l}\text { Receptores de } \\
\text { integrina }\end{array}$ & $5 / 6$ & $2 / 6$ & $0 / 6$ & $0 / 6$ & $1 / 6$ & $0 / 6$ \\
\hline Colágeno & $12 / 16$ & $4 / 16$ & $0 / 16$ & $0 / 16$ & $0 / 16$ & $2 / 16$ \\
\hline $\begin{array}{l}\text { Relacionados à } \\
\text { cartilagem }\end{array}$ & $2 / 2$ & $1 / 2$ & $0 / 2$ & $0 / 2$ & $0 / 2$ & $0 / 2$ \\
\hline Metaloproteinases & $3 / 4$ & $1 / 4$ & $0 / 4$ & $0 / 4$ & $0 / 4$ & $0 / 4$ \\
\hline $\begin{array}{l}\text { Fatores de } \\
\text { transcrição }\end{array}$ & $8 / 8$ & $2 / 8$ & $0 / 8$ & $0 / 8$ & $0 / 8$ & $0 / 8$ \\
\hline Outros genes & $5 / 9$ & $1 / 9$ & $2 / 9$ & $0 / 9$ & $1 / 9$ & $0 / 9$ \\
\hline
\end{tabular}




\section{DISCUSSÃO}

No presente estudo in vitro avaliou-se o desenvolvimento do fenótipo osteogênico de células pré-osteoblásticas da linhagem MC3T3-E1, bem como o perfil de expressão de genes relacionados à osteogênese em momentos distintos da progressão dessas culturas sobre superfícies de materiais vítreos e vitrocerâmicos bioativos. Os resultados mostraram diferenças significantes no potencial osteogênico das células MC3T3-E1 sobre os diferentes substratos, maior para os materiais bioativos, que correspondem a uma expressão diferencial de genes durante as fases 1) proliferativa, 2) de diferenciação osteoblástica e de síntese e maturação da matriz extracellular e 3) de mineralização da matriz extracelular. Entre os materiais bioativos testados, maior mineralização foi observada em culturas sobre Bio-sc, as quais exibem maiores proporções de inibição de genes dos diferentes grupos em 7 dias e de sobre-expressão, em 12 e 21 dias, em um perfil que as distingue das culturas sobre $45 \mathrm{~S} 5$ e Bio.

Materiais vítreos e vitrocerâmicos bioativos vêm sendo desenvolvidos nas últimas décadas para diferentes aplicações nas áreas médicas e odontológicas, o que inclui Bioglass ${ }^{\circledR} 45 S 5$ (Biogran $^{\circledR}$ e Perioglas ${ }^{\circledR}$ ), A/W ${ }^{\circledR}$ (apatita-wolastonita) e Biosilicato $^{\circledR}$ (BELLUCCl et al., 2010). Dependendo do tipo de defeito ósseo a ser tratado, devem, idealmente, ser preparados como partículas de diferentes dimensões ou scaffolds. Quando exposta a fluidos biológicos, a superfície desses materiais, diferentemente da de vidros bioinertes como o borosilicato, exibem modificações químicas e topográficas que resultam na formação de uma camada de hidroxicarbonatoapatita (HCA) sobre sílica-gel (HENCH; WILSON, 1984; ANDRADE; 
DOMINGUES, 2006). Apesar de conceitos clássicos de bioatividade estarem relacionados à velocidade com que essas reações ocorrem em fluido corporal simulado (SBF, na sigla em inglês), com formação mais rápida de HCA correspondendo à maior bioatividade, e à habilidade do material de se ligar à matriz óssea, aspectos favoráveis de interação de células com os substratos reativos e de formação tecidual na região interfacial podem não estar associados exclusivamente aos materiais mais bioativos (revisado por Bellucci et al., 2010). Assim, modelos experimentais in vitro e in vivo devem considerar avaliações de um amplo espectro de parâmetros para uma maior compreensão dos efeitos biológicos sobre células e tecidos na dependência do nível de bioatividade do material vítreo ou vitrocerâmico.

As vitrocerâmicas são desenvolvidas a partir da cristalização controlada de vidros por diferentes protocolos de tratamento térmico (PEITL et al., 2001; CROVACE, 2009; PEITL et al., 2012). Apesar de estudos mostrarem a redução da bioatividade de vidros bioativos por adição de novas fases cristalinas ao material vítreo (revisado por Bellucci et al., 2010), alta bioatividade foi observada para o Biosilicato $^{\circledR}$ em comparação ao vidro que lhe deu origem (Biosilicato ${ }^{\circledR}$ vítreo) e ao Bioglass $^{\circledR}$ 45S5, gold standard pertencente ao mesmo sistema quaternário, determinada pelos resultados de exposição ao SBF e de maior potencial osteogênico de culturas primárias de células osteoblásticas (MOURA et al., 2007). Apesar de esses resultados in vitro sugerirem efeitos positivos do Biosilicato ${ }^{\circledR}$ sobre o processo de reparo ósseo, confirmado por Granito et al. $(2009,2011)$ utilizando material particulado em defeitos ósseos de ratos, o desenvolvimento de scaffolds desse material dependeria de modificações no protocolo de tratamento térmico visando à formação de estruturas tridimensionais com poros interconectados. Em sua aplicação clínica, essas estruturas deveriam permitir, idealmente, o carreamento 
de células e/ou fatores de crescimento, bem como o estímulo e o direcionamento da neoformação óssea durante o processo de reparação tecidual (ROSA et al., 2008). Neste contexto, Crovace (2009), por meio de sinterização controlada do Biosilicato ${ }^{\circledR}$, obteve scaffolds com bioatividade comparável à do Bioglass ${ }^{\circledR} 45 S 5$, mesmo com a adição de nova fase cristalina, de fosfato de cálcio, de alta reatividade, na proporção da ordem de $5 \%$, e com porosidade que variava na dependência da técnica utilizada para a síntese dos scaffolds, se por réplica ou por adição de agentes porogênicos. Os resultados de nosso estudo in vitro, utilizando esta preparação de Biosilicato ${ }^{\circledR}$ estruturada em discos destituídos de poros, indicam que o Bio-sc favorece, diferencialmente em relação aos demais materiais avaliados, o desenvolvimento do fenótipo osteogênico, o que, provavelmente, corresponderia ao estímulo à formação óssea in vivo com a implantação de scaffolds de Bio-sc em defeitos ósseos. Além disso, o Bio-sc poderia ser também utilizado como material particulado com vantagens, substituindo a preparação original de Biosilicato ${ }^{\circledR}$, cujas avaliações in vitro e in vivo já indicavam benefícios aos processos de diferenciação osteoblástica e de reparação do tecido ósseo, respectivamente (MOURA et al., 2007; GRANITO et al., 2009; GRANITO et al., 2011).

O modelo experimental utilizado neste trabalho para avaliar a diferenciação osteoblástica sobre materiais vítreos e vitrocerâmicos bioativos foi o de células préosteoblásticas da linhagem MC3T3-E1, subclone 14, de camundongo, cujos eventos sequenciais de aquisição do fenótipo osteoblástico maduro assemelham-se aos de osteoblastos durante a formação do tecido ósseo in vivo (QUARLES et al., 1992). Essas características das culturas de células MC3T3-E1 permitiram avaliar se os efeitos do crescimento dessas células sobre os diferentes materiais na expressão de genes relacionados ao tecido ósseo seriam diferentes em momentos distintos da 
cultura, representando as fases proliferativa (1-9 dias), de diferenciação osteoblástica e de síntese e maturação da matriz extracelular (9-16 dias) e de mineralização da matriz extracelular (16-21 dias). Assim, a opção pelos tempos de avaliação de 7, 12 e 21 dias resultou na observação de aspectos diferenciais no perfil de expressão gênica entre os materiais bioativos em comparação ao controle bionerte (Boro), entre as duas preparações de Biosilicato ${ }^{\circledR}$ quando comparadas ao controle bioativo (45S5) e entre os tempos experimentais. Isso poderia ser devido a diferenças na dinâmica das reações de superfície dos materiais bioativos, ausentes no borosilicato, cujos produtos de dissolução iônica podem afetar a expressão gênica em células osteoblásticas (HENCH et al., 2000; XYNOS et al., 2001; LOTY et al., 2001; HENCH et al., 2002; ANDRADE; DOMINGUES, 2006). Além disso, o processo complexo de adsorção de proteínas do soro sobre os substratos reativos poderia ser afetado, temporalmente, pelas modificações sequenciais na composição química e energia de superfície, com efeitos sobre a sinalização celular via transdução de sinais; diferenças na cristalinidade dos materiais provavelmente não afetariam a adsorção de proteínas (BAHNIUK et al., 2012).

Com base nestes aspectos e nos resultados deste estudo in vitro, seria relevante avaliar em estudos futuros o Bio-sc em relação às características de superfície deste material, quando exposto a fluidos biológicos, que sejam fatores determinantes para os efeitos de maior diferenciação e atividade osteoblástica na região interfacial. Adicionalmente, para potenciais aplicações clínicas do Bio-sc, seria essencial a confirmação do estímulo à formação óssea em modelos experimentais in vivo de defeitos ósseos. 


\section{CONCLUSÃO}

Os resultados do presente estudo permitem concluir que:

1) células MC3T3-E1 cultivadas sobre as superfícies de materiais vítreos e vitrocerâmicos exibiram aumentos progressivos da população celular e da diferenciação osteoblástica, que resultaram em diferenças significativas na intensidade de mineralização da matriz extracelular entre os materiais, na seguinte ordem crescente: Boro < 45S5 < Bio < Bio-sc;

2) houve expressão diferencial de genes em fases distintas da progressão de células MC3T3-E1 para as comparações entre os materiais bioativos e o bioinerte e entre as duas preparações de Biosilicato ${ }^{\circledR}$ e o Bioglass ${ }^{\circledR} 45 S 5$;

3) dentre os materiais avaliados, o Biosilicato ${ }^{\circledR}$ para scaffold favorece o maior potencial osteogênico de células MC3T3-E1, cujas maiores proporções de inibição de genes dos diferentes grupos ocorre em 7 dias, e de sobre-expressão, em $12 \mathrm{e}^{\text {- }}$ dias, em um perfil que as distingue das culturas sobre Biosilicato ${ }^{\circledR}$ e Bioglass ${ }^{\circledR} 45 S 5$. 
7 REFERÊNCIAS BIBLIOGRÁFICAS 


\section{REFERÊNCIAS BIBLIOGRÁFICAS}

ANDRADE AL, DOMINGUES RZ. Cerâmicas bioativas - estado da arte. Quim Nova 2006; 29:100-104.

BELLUCCI D, CANNILLO V, SOLA A. An overview of the effects of thermal processing on bioactive glasses. Sci Sinter 2010; 42:307-320.

BAHNIUK MS, PIRAYESH H, SINGH HD, NYCHKA JA, UNSWORTH LD. Bioactive glass $45 S 5$ powders: effect of synthesis route and resultant surface chemistry and crystallinity on protein adsorption from human plasma. Biointerphases 2012;7:41.

BRÖMER H, KAES HH, PFEIL E (to Ernst Leitz GmbH). Biocompatible glass ceramic material. US Patent Documents No. 3,981,736, 21 Sep. 1976. Int. C. A61F001/00.

BRUNSKI JB, PULEO DA, NANCI A. Biomaterials and biomechanics of oral and maxillofacial implants: current status and future developments. Int $\mathrm{J}$ Oral Maxillofac Implants 2000; 15:15-46.

CHEN QZ, THOMPSON ID, BOCCACCINI AR. 45S5 Bioglass ((R))-derived glassceramic scaffolds for bone tissue engineering. Biomaterials 2006; 27:2414-2425.

CROVACE MC. Obtenção de estruturas porosas altamente bioativas via sinterização do Biosilicato ${ }^{\circledR}$. 2009. 117p. Dissertação (Mestrado em Ciência e Engenharia de Materiais) - Centro de Ciências Exatas e de Tecnologia da Universidade Federal de São Carlos, São Carlos.

DE CASTRO LMS. Osteogênese in vitro sobre vitrocerâmica $100 \%$ cristalina e altamente bioativa $\left(\right.$ Biosilicato ${ }^{\circledR}$ ): efeitos do condicionamento de superfície e dos produtos de dissolução iônica. 2009. 98 p. Dissertação (Mestrado em Biologia Oral) - Faculdade de Odontologia de Ribeirão Preto da Universidade de São Paulo, Ribeirão Preto.

DE OLIVEIRA PT, NANCI A. Nanotexturing of titanium-based surfaces upregulates expression of bone sialoprotein and osteopontin by cultured osteogenic cells. Biomaterials 2004; 25:403-413.

DE OLIVEIRA PT, ZALZAL SF, BELOTI MM, ROSA AL, NANCI A. Enhancement of in vitro osteogenesis on titanium by chemically produced nanotopography. $J$ Biomed Mater Res A 2007; 80:554-564. 
DE OLIVEIRA PT, ZALZAL SF, IRIE K, NANCI A. Early expression of bone matrix proteins in osteogenic cell cultures. J Histochem Cytochem 2003; 51:633-641.

DUCHEYNE P, QIU Q. Bioactive ceramics: the effect of surface reactivity on bone formation and bone cell function. Biomaterials 1999; 20:2287-2303.

FRATZL-ZELMAN N, FRATZL $P$, HÖRANDNER $H$, GRABNER B, VARGA $F$, ELLINGER A, KLAUSHOFER K. Matrix mineralization in MC3T3-E1 cell cultures initiated by beta-glycerophosphate pulse. Bone 1998; 23:511-520.

GRANITO RN, RIBEIRO DA, RENNÓ AC, RAVAGNANI C, BOSSINI PS, PEITLFILHO O, ZANOTTO ED, PARIZOTTO NA, OISHI J. Effects of biosilicate and bioglass $45 \mathrm{~S} 5$ on tibial bone consolidation on rats: a biomechanical and a histological study. J Mater Sci Mater Med 2009; 20:2521-2526.

HATTAR S, ASSELIN A, GREENSPAN D, OBOEUF M, BERDAL A, SAUTIER JM. Potential of biomimetic surfaces to promote in vitro osteoblast-like cell differentiation. Biomaterials 2005; 26:839-848.

HENCH LL, POLAK JM. Third-generation biomedical materials. Science 2002; 295:1014-1017.

HENCH LL, POLAK JM, XYNOS ID, BUTTERY LDK. Bioactive materials to control cell cycle. Mat Res Innovat 2000; 3:313-323.

HENCH LL, WEST JK. Biological applications of bioactive glasses. Life Chem Reports 1996; 13:187-241.

HENCH LL, WILSON J. An introduction to bioceramics. Singapore: World Scientific, 1993. $386 \mathrm{p}$.

HENCH LL, WILSON J. Surface-active biomaterials. Science 1984; 226:630-636.

IRIE K, ZALZAL S, OZAWA H, MCKEE MD, NANCI A. Morphological and immunocytochemical characterization of primary osteogenic cell cultures derived from fetal rat cranial tissue. Anat Rec 1998; 252:554-567.

JAMES PF. Glass ceramics: new compositions and uses. J Non-Cryst Solids 1995; 181:1-15. 
KOKUBO T, ITO S, SHIGEMATSU M, YAMAMURO T. Mechanical properties of a new type of apatite-containing glass-ceramic for prosthetic application. J Mater Sci 1985; 20:2001-2004.

LIVAK KL, SCHMITTGEN TD. Analysis of relative gene expression data using realtime quantitative PCR and the 22DDCT method. Methods 2001; 25:402-408.

LOSSDORFER S, SCHWARTZ Z, WANG L, LOHMANN CH, TURNER JD, WIELAND $M$, COCHRAN DL, BOYAN BD. Microrough implant surface topographies increase osteogenesis by reducing osteoclast formation and activity. J Biomed Mater Res A 2004; 70:361-369.

LOTY C, SAUTIER JM, TAN MT, OBOEUF M, JALLOT E, BOULEKBACHE H, GREENSPAN D, FOREST N. Bioactive glass stimulates in vitro osteoblast differentiation and creates a favorable template for bone tissue formation. J Bone Miner Res 2001; 16:231-239.

MOFFATT P, GAUMOND MH, SALOIS P, SELLIN K, BESSETTE MC, GODIN E, DE OLIVEIRA PT, ATKINS GJ, NANCI A, THOMAS G. Bril: a novel bone-specific modulator of mineralization. J Bone Miner Res 2008; 23:1497-1508.

MOORE WR, GRAVES SE, BAIN GI. Synthetic bone graft substitutes. ANZ J Surg $2001 ; 71: 354-361$.

MOURA J, TEIXEIRA LN, RAVAGNANI C, PEITL O, ZANOTTO ED, BELOTI MM, PANZERI $\mathrm{H}$, ROSA AL, DE OLIVEIRA PT. In vitro osteogenesis on a highly bioactive glass-ceramic (Biosilicate). J Biomed Mater Res A 2007; 82:545-557.

NANCI A, MCKEE MD, ZALZAL S, SAKKAL S. Ultrastructural and immunocytochemical analysis of the tissue response to metal implants in the rat tibia. In: DAVIDOVITCH, Z.; MAH, J. eds. Biological mechanisms of tooth eruption, resorption and replacement by implants. Boston: Harvard Society for the Advancement of Orthodontics, 1998; 487-500.

NANCI A, ZALZAL S, GOTOH Y, MCKEE MD. Ultrastructural characterization and immunolocalization of osteopontin in rat calvarial osteoblast primary cultures. Microsc Res Tech 1996; 33:214-231.

PEITL O, ZANOTTO ED, HENCH LL. Highly bioactive $\mathrm{P}_{2} \mathrm{O}_{5}-\mathrm{Na}_{2} \mathrm{O}-\mathrm{CaO}-\mathrm{SiO}_{2}$ glassceramics. J Non-Cryst Solids 2001; 292:115-126. 
PEITL O, ZANOTTO ED, SERBENA FC, HENCH LL. Compositional and microstructural design of highly bioactive $\mathrm{P} 2 \mathrm{O} 5-\mathrm{Na} 2 \mathrm{O}-\mathrm{CaO}-\mathrm{SiO} 2$ glass-ceramics. Acta Biomater 2012; 8:321-332.

PULEO DA, HOLLERAN LA, DOREMUS RH, BIZIOS R. Osteoblast responses to orthopedic implant material in vitro. J Biomed Mater Res 1991; 25:711-723.

QUARLES LD, YOHAY DA, LEVER LW, CATON R, WENSTRUP RJ. Distinct proliferative and differentiated stages of murine MC3T3-E1 cells in culture: an in vitro model of osteoblast development. J Bone Miner Res 1992; 7:683-692.

ROSA AL, DE OLIVEIRA PT, BELOTI MM. Macroporous scaffolds associated with cells to construct a hybrid biomaterial for bone tissue engineering. Expert Rev Med Devices 2008; 5:719-728.

RENNO AC, MCDONNELL PA, CROVACE MC, ZANOTTO ED, LAAKSO L. Effect of $830 \mathrm{~nm}$ laser phototherapy on osteoblasts grown in vitro on Biosilicate scaffolds. Photomed Laser Surg 2010; 28:131-133.

RORIZ VM, ROSA AL, PEITL O, ZANOTTO ED, PANZERI H, DE OLIVEIRA PT. Efficacy of a bioactive glass-ceramic (Biosilicate) in the maintenance of alveolar ridges and in osseointegration of titanium implants. Clin Oral Implants Res 2010; 21:148-155.

SCHWARTZ FO HO, NOVAES AB JR, DE CASTRO LMS, ROSA AL, DE OLIVEIRA $\mathrm{PT}$. In vitro osteogenesis on a microstructured titanium surface with additional submicron-scale topography. Clin Oral Implants Res 2007; 18:333-344.

VETRONE F, VARIOLA F, TAMBASCO DE OLIVEIRA P, ZALZAL SF, YI JH, SAM J, BOMBONATO-PRADO KF, SARKISSIAN A, PEREPICHKA DF, WUEST JD, ROSEl F, NANCl A. Nanoscale oxidative patterning of metallic surfaces to modulate cell activity and fate. Nano Lett 2009; 9:659-665.

XYNOS ID, EDGAR AJ, BUTTERY LD, HENCH LL, POLAK JM. Ionic products of bioactive glass dissolution increase proliferation of human osteoblasts and induce insulin-like growth factor II mRNA expression and protein synthesis. Biochem Biophys Res Commun 2000; 276:461-465.

XYNOS ID, EDGAR AJ, BUTTERY LD, HENCH LL, POLAK JM. Gene-expression profiling of human osteoblasts following treatment with the ionic products of Bioglass 45S5 dissolution. J Biomed Mater Res 2001; 55:151-157. 